\title{
Simulations of Ground Motion in the Los Angeles Basin Based upon the Spectral-Element Method
}

\author{
by Dimitri Komatitsch, Qinya Liu, Jeroen Tromp, Peter Süss, ${ }^{*}$ Christiane Stidham, \\ and John H. Shaw
}

\begin{abstract}
We use the spectral-element method to simulate ground motion generated by two recent and well-recorded small earthquakes in the Los Angeles basin. Simulations are performed using a new sedimentary basin model that is constrained by hundreds of petroleum-industry well logs and more than $20,000 \mathrm{~km}$ of seismic reflection profiles. The numerical simulations account for 3D variations of seismicwave speeds and density, topography and bathymetry, and attenuation. Simulations for the 9 September $2001 M_{\mathrm{w}} 4.2$ Hollywood earthquake and the 3 September 2002 $M_{\mathrm{w}} 4.2$ Yorba Linda earthquake demonstrate that the combination of a detailed sedimentary basin model and an accurate numerical technique facilitates the simulation of ground motion at periods of $2 \mathrm{sec}$ and longer inside the basin model and $6 \mathrm{sec}$ and longer in the regional model. Peak ground displacement, velocity, and acceleration maps illustrate that significant amplification occurs in the basin.
\end{abstract}

\section{Introduction}

Accurate prediction of hazardous ground shaking generated by large earthquakes requires the ability to numerically simulate seismic-wave propagation in realistic geological models. In this article we demonstrate that, using a detailed model of the Los Angeles, California, basin (Fig. 1) and an accurate numerical technique, ground motion can be accurately modeled down to a period of $2 \mathrm{sec}$ inside the basin model and $6 \mathrm{sec}$ in the regional model.

The Los Angeles basin developed in the Neogene as a result of regional crustal extension associated with the opening of the California Borderlands and rotation of the Transverse Ranges (Luyendyk and Hornafius, 1987; Wright, 1991). Since the early Pliocene, the basin has been deformed by numerous strike-slip, reverse, and blind-thrust faults that accommodate oblique convergence between the Pacific and North American plates (e.g., Davis et al., 1989; Hauksson, 1990; Wright, 1991; Schneider et al., 1996; Shaw and Suppe, 1996; Shaw and Shearer, 1999; Fuis et al., 2003). This tectonic history, combined with varied depositional and diagenetic processes involving the basin sediments, has yielded complex 3D wave-speed and density structures in the Los Angeles basin (e.g., Süss and Shaw, 2003).

Regional studies initially focused on developing average 1D models (e.g., Hadley and Kanamori, 1977; Dreger and Helmberger, 1990). Three-component broadband records of small earthquakes were used in Dreger and Helm-

\footnotetext{
Now at Institut für Geologie und Paläontologie, University of Tübingen, Sigwartstrasse 10, 72076 Tübingen, Germany.
}

berger (1990) to study the sensitivity of synthetic seismograms to perturbations of the crustal model and to construct an average 1D layered model of crustal structure. More recently, taking advantage of the large number of broadband seismic stations and the related wealth of high-quality data, regional tomographic $V_{\mathrm{p}}$ and $V_{\mathrm{p}} / V_{\mathrm{s}}$ models have been constructed (e.g., Hauksson and Haase, 1997; Hauksson, 2000) based upon $P$ and $S-P$ travel times from local earthquakes and controlled artificial sources. The 3D shape of the southern California Moho has also been imaged (e.g., Ichinose et al., 1996; Lewis et al., 2000; Zhu and Kanamori, 2000). Based upon the teleseismic receiver function technique, Zhu and Kanamori (2000) have shown that very significant variations of Moho depth exist in the region, from 21 to $37 \mathrm{~km}$, with a regional average of $29 \mathrm{~km}$. A deep Moho is found under the eastern Transverse Range, the Peninsular Range, and the Sierra Nevada Range. To the contrary, the central Transverse Range does not have a deep continental root. The crust is much thinner (typically $21-22 \mathrm{~km}$ ) in the Inner California Borderland and the Salton Trough. In the past few years, the Southern California Earthquake Center (SCEC) has focused on creating 3D wave-speed models of the region (e.g., Magistrale et al., 1996, 2000; Graves, 1999). The SCEC model is a rule-based wave-speed description, calibrated with seven sonic logs, that relates $V_{\mathrm{p}}$ to the age and depth of strata. In contrast, the model we use for our simulations is interpolated from more than 150 sonic logs and 7000 stacking velocities derived from petroleum-industry reflection profiles (Süss and Shaw, 2003). The two models 


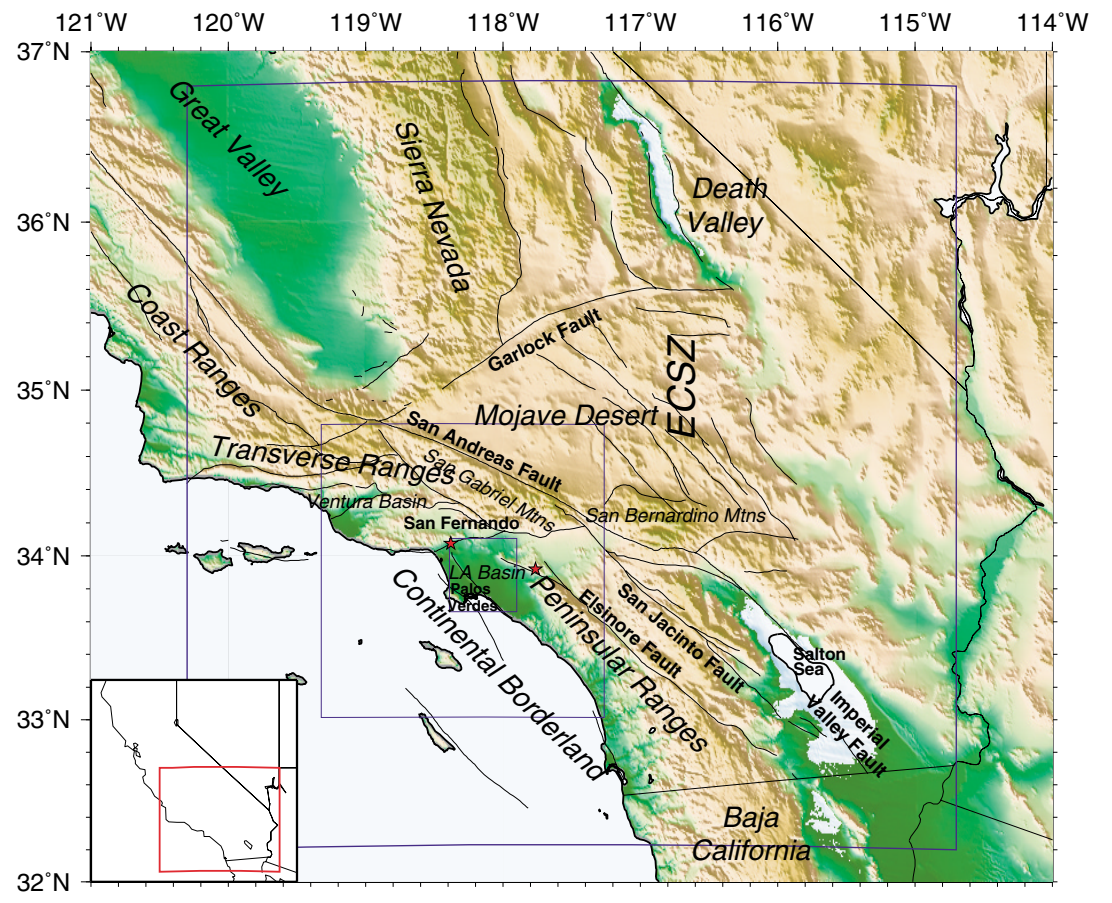

Figure 1. Topographic map of southern California showing the Los Angeles region. The small California map in the lower lefthand corner shows the location of the area represented (red rectangle). The main late Quaternary faults (Jennings, 1975) are also displayed. ECSZ, Eastern California Shear Zone. TriNet stations are indicated by white triangles. The large blue rectangle shows the edges of the computer grid that we use to perform our 3D ground-motion calculations. The two smaller blue rectangles are the edges of the mediumand high-resolution Los Angeles basin models, respectively. The epicenters of the Hollywood and Yorba Linda earthquakes studied in this article are denoted by red stars.

have similar average velocity functions, but our model describes more detailed lateral and vertical wave-speed structure that is observed in borehole and stacking velocity data.

Accurate numerical techniques are needed in order to understand ground motion in complex 3D structures and to study past large earthquakes or hypothetical earthquake scenarios and their impact in terms of seismic hazard, building codes, disaster prevention, and emergency planning. $\mathrm{Nu}-$ merical simulations of ground motion in complex heterogeneous structures have previously been performed based upon techniques that can handle highly heterogeneous 3D models, such as the finite-difference (e.g., Boore, 1972; Frankel and Leith, 1992; Frankel and Vidale, 1992; McLaughlin and Day, 1994; Olsen et al., 1995; Pitarka and Irikura, 1996a; Antolik et al., 1996; Larsen et al., 1997; Kristek et al., 1999; Stidham et al., 1999; Ji et al., 2000; Satoh et al., 2001) and finite-element methods (e.g., Lysmer and Drake, 1972; Bao et al., 1998; Bielak et al., 1999; Garatani et al., 2000; Aagaard et al., 2001).

Several studies have focused more specifically on southern California and the Los Angeles basin (e.g., Frankel, 1993; Olsen and Archuleta, 1996; Pitarka and Irikura, 1996b; Olsen et al., 1997; Wald and Graves, 1998; Graves, 1999; Olsen, 2000; Peyrat et al., 2001; Eisner and Clayton, 2002). The complexity of the seismic response of the Los Angeles basin has been analyzed by many authors in recent years, for example, Hartzell et al. (1996, 1998), Wald and Graves (1998), and Olsen (2000). Detailed reviews are available in particular in Wald and Graves (1998) and Olsen (2000). There is evidence that large amplification (factors of 3,4 , or more) can occur between basin sites and hard-rock sites. It has also been shown that site effects caused by to- pography or local geological features, such as poorly consolidated sediments, can result in very significant amplification of the wave field (e.g., Gaffet and Bouchon, 1989; Frankel and Leith, 1992; Stevens et al., 1993). Such phenomena have been observed in the Los Angeles region, for example, very large accelerations (up to $1.8 g$ ) at Tarzana Hill during the 1994 Northridge earthquake (e.g., Bouchon and Barker, 1996; Catchings and Lee, 1996; Rial, 1996; Spudich et al., 1996; Komatitsch and Vilotte, 1998). Localization effects can also cause important damage, as illustrated in Santa Monica during the 1994 Northridge earthquake (e.g., Gao et al., 1996; Alex and Olsen, 1998; Davis et al., 2000). Such effects are intrinsically 3D and therefore further illustrate the need for detailed basin models and accurate and flexible numerical techniques.

In this article, we present simulations based on a detailed model of the Los Angeles basin (Süss and Shaw, 2003) and a powerful numerical technique called the spectralelement method (SEM). Using two recent well-recorded small $\left(M_{\mathrm{w}}\right.$ 4.2) earthquakes in the basin, we show that ground motion can be accurately modeled down to a period of $2 \mathrm{sec}$ inside the basin model and $6 \mathrm{sec}$ in the regional model. The SEM has several distinct advantages over more classical numerical techniques mentioned earlier, as will be illustrated in the Numerical Technique section.

\section{Basin Model}

Creating a high-resolution wave-speed model of the Los Angeles basin (Fig. 1) has been the focus of significant attention in recent years. Collaborative efforts in the context of the SCEC have led to the development of models that are 
now widely used in the geophysical community (e.g., Magistrale et al., 1996, 2000; Hauksson and Haase, 1997; Graves, 1999). In this article, we use an extension of the more recent model of Süss and Shaw (2003), which describes a complex, heterogeneous 3D wave-speed structure (Figs. 2 and 3) based on more than 85,000 direct measurements from petroleum-industry boreholes and seismic reflection profiles. The model contains a description of the sedimentary basin shape as defined by the contact between lower wave-speed sediments and the higher wave-speed crystalline basement. Wave speeds within the sedimentary sequence were interpolated from sonic log and stacking velocity measurements using geostatistical kriging techniques (Süss and Shaw, 2003). The resultant wave-speed structure is highly complex, reflecting sedimentary, diagenetic, and structural controls, and is substantially different from previous descriptions mentioned earlier. While the original model (Süss and Shaw, 2003) covered only parts of the San Fernando Valley, the improved model used in this article includes the San Fernando, Ventura, Soledad, and Ridge basins and extends northward beyond the Ventura Basin. We constructed a surface defining the top of the crystalline basement for this area, and wave speeds east of the San Andreas Fault were taken from the tomographic model of Hauksson (2000). The top of the crystalline basement in the Ventura Basin was constructed based upon reference surfaces taken from the SCEC-II model (Magistrale et al., 2000), as well as cross sections from Yeats et al. (1994) and Huftile and Yeats
(1995). The geometry of the Ridge basin and Soledad basin was approximated based upon cross sections in Namson and Davis (1992).

The model and supporting data constrain compressional-wave $\left(P\right.$-wave) speed $\left(V_{\mathrm{p}}\right)$. Shear-wave $(S$-wave $)$ speed $\left(V_{\mathrm{s}}\right)$ and density $(\rho)$ models, which are also needed for the simulations, were derived from the $V_{\mathrm{p}}$ model using simple empirical relations. More specifically, $S$-wave speed $V_{\mathrm{s}}$ is defined by dividing $V_{\mathrm{p}}$ by a coefficient that varies linearly from 1.732 in the deepest part of the basin (i.e., a Poisson's ratio of 0.25 at a depth of $8.5 \mathrm{~km}$ ) to 2 in the shallow sediments near the surface (i.e., a Poisson's ratio of 0.33 at the surface). Based upon well-log information, density is defined by $\rho=V_{\mathrm{p}} / 3+1280$ (McCulloh, 1960; Stidham et al., 2001), imposing a minimum of $2000 \mathrm{~kg} \mathrm{~m}^{-3}$.

The basin model is embedded in the regional tomographic model of Hauksson (2000), which gives $P$ - and $S$ wave speeds in southern California. In addition, we use the 1D background regional model of Dreger and Helmberger (1990). Note that, by lack of information about density in the area where the tomographic model of Hauksson (2000) is used, we use the 1D regional density profile of Dreger and Helmberger (1990). Until recently, little was known about attenuation in the Los Angeles basin, but low values of the shear quality factor $Q_{\mu}$ had been observed (Hauksson et al., 1987). Based upon the work of Hauksson et al. and trialand-error numerical tests, we decided to use a constant value of $Q_{\mu}=90$ in the sediments and no attenuation in the bed-

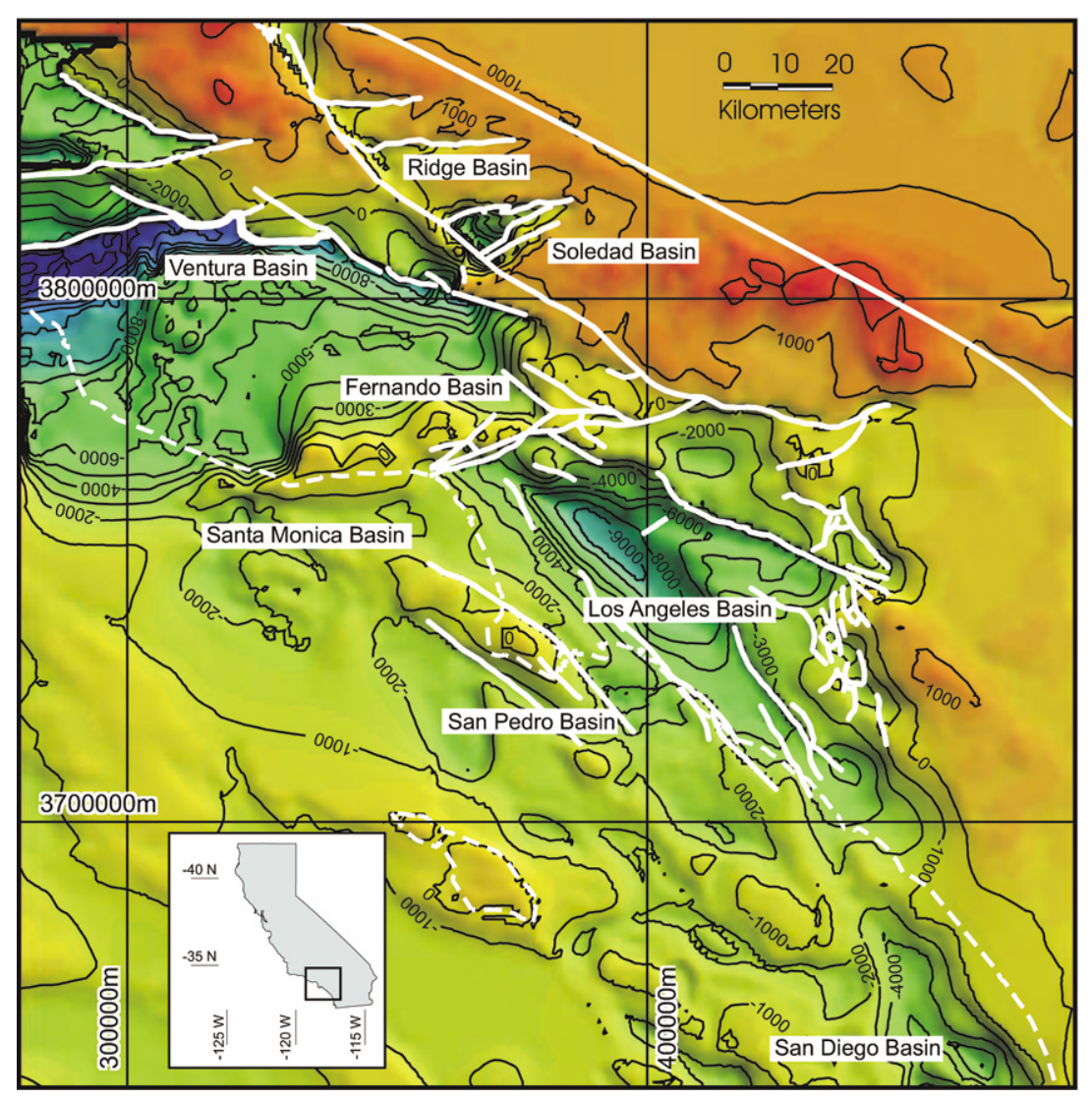

Figure 2. Top view of the surface defining the top of the crystalline basement in the Los Angeles basin model. The coastline is indicated by the white dashed line, and major faults by white solid lines. Red regions denote shallow sediments or no sediments at all, and green and blue the deepest sediments. One can clearly see the deep sedimentary pocket underneath Los Angeles, as well as the very sharp Ventura escarpment. 
(a)

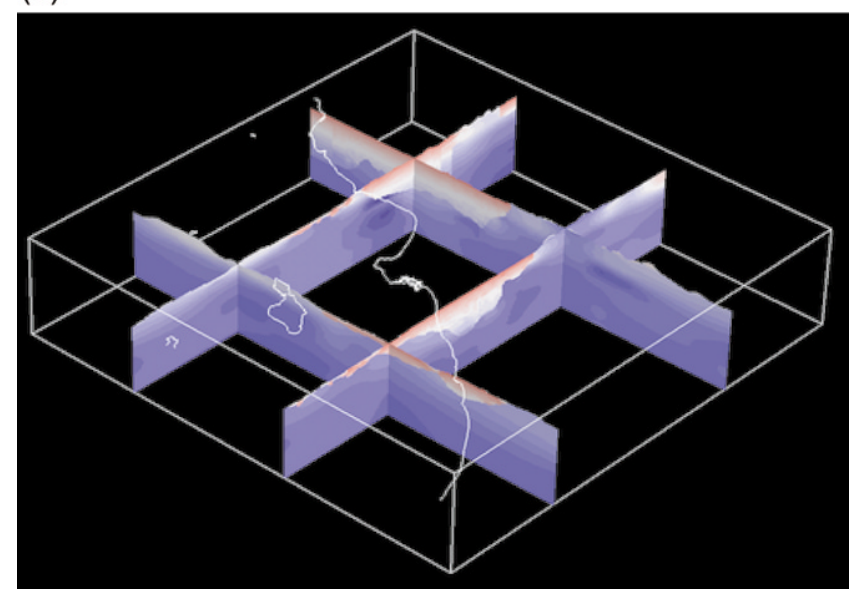

(b)

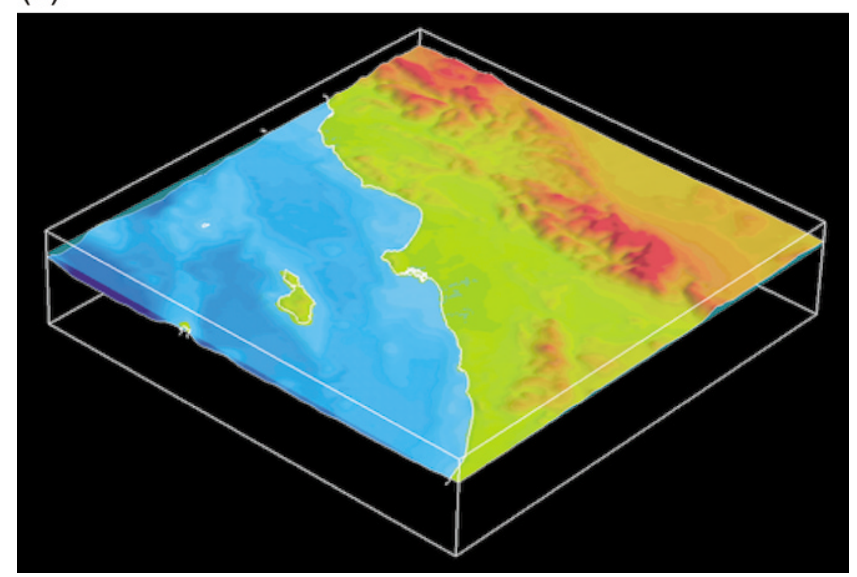

Figure 3. View from the southeast upon the Los Angeles basin model. (a) North-south and east-west cross sections showing $P$-wave speed in the basin model, with blue denoting fast bedrock and white and red slower deep and shallow sediments, respectively. The coastline is shown by the white line. The maximum depth of the basin is $8.5 \mathrm{~km}$ underneath downtown Los Angeles. The basin model is embedded into the regional tomographic model of Hauksson (2000) (not shown here). (b) Surface topography and bathymetry. One can clearly see the San Gabriel mountains toward the north, Palos Verdes along the coast, as well as the Ventura, San Fernando, and Los Angeles basins.

rock. It would ultimately be of interest to use the recent attenuation scaling rules of Olsen et al. (2003). Lateral variations in crustal thickness are incorporated based upon the regional Moho model of Zhu and Kanamori (2000). Topography and bathymetry are obtained from a U.S. Geological Survey (USGS) digital elevation map (USGS, 2003), as illustrated in Figure 3.

\section{Numerical Technique}

We use the SEM to simulate ground motion in the basin, based upon the linear anelastic wave equation. Nonlinear effects are not taken into account in this article. The SEM is a highly accurate numerical method that has its origins in computational fluid dynamics (Patera, 1984). It uses a mesh of hexahedral finite elements on which the wave field is represented in terms of high-degree Lagrange polynomials on Gauss-Lobatto-Legendre interpolation points. The method was used to model seismic-wave propagation in local and regional models in the 1990s (e.g., Cohen et al., 1993; Priolo et al., 1994; Faccioli et al., 1997; Komatitsch, 1997; Komatitsch and Vilotte, 1998; Komatitsch and Tromp, 1999). It was more recently introduced for global wave propagation by Chaljub (2000) and extended for large-scale global wave propagation (Komatitsch and Tromp, 2002a,b; Capdeville et al., 2003; Chaljub et al., 2003).

The main advantage of the SEM is that it combines the flexibility of the finite-element method (e.g., Lysmer and Drake, 1972; Moczo et al., 1997; Bao et al., 1998; Bielak et al., 1999; Garatani et al., 2000) with the accuracy of pseudospectral techniques (e.g., Tessmer et al., 1992; Carcione and Wang, 1993; Igel, 1999). It is more accurate than widely used classical techniques such as the finite-difference method (e.g., Boore, 1972; Virieux, 1986; Graves, 1996; Olsen et al., 1997), in particular for surface waves (e.g., Komatitsch and Tromp, 1999, 2002a), which play an important role in ground-motion seismology.

In the SEM, it is relatively straightforward to densify the mesh near the surface of the model in the low wave-speed sediments, using mesh doubling as a function of depth, as illustrated in Figure 4, assuming that the surfaces do not exhibit large local variations (i.e., that they are smooth enough). Using a coarser mesh in depth significantly reduces the memory requirements and facilitates an increase in the value of the time step, thus enabling larger simulations for a similar computational cost. Due to the geometrical flexibility that the SEM shares with the finite-element method, the mesh can be adapted to topography and bathymetry as well as the shape of the basement surface and the Moho (Fig. 4). Even in the presence of substantial topography, the traction-free boundary condition at the Earth's free surface is satisfied automatically in a SEM (e.g., Komatitsch and Vilotte, 1998; Komatitsch and Tromp, 1999, 2002a).

The choice of high-degree Lagrange polynomial interpolants combined with Gauss-Lobatto-Legendre quadrature results in minimal numerical grid dispersion. Because of this particular choice of integration points and numerical integration rule, the SEM's most important property is an exactly diagonal mass matrix, which leads to a simple explicit time integration scheme without needing to solve a system of linear equations (e.g., Komatitsch and Vilotte, 1998; Komatitsch and Tromp, 1999, 2002a). Because of the fact that the mass matrix is exactly diagonal, another property of the SEM is that it is very well adapted to the parallel distributed memory architecture of modern computers (Komatitsch and Tromp, 2001; Komatitsch et al., 2003), an advantage it shares with the finite-difference method. This implies that the SEM is simpler to implement than traditional finiteelement methods. 


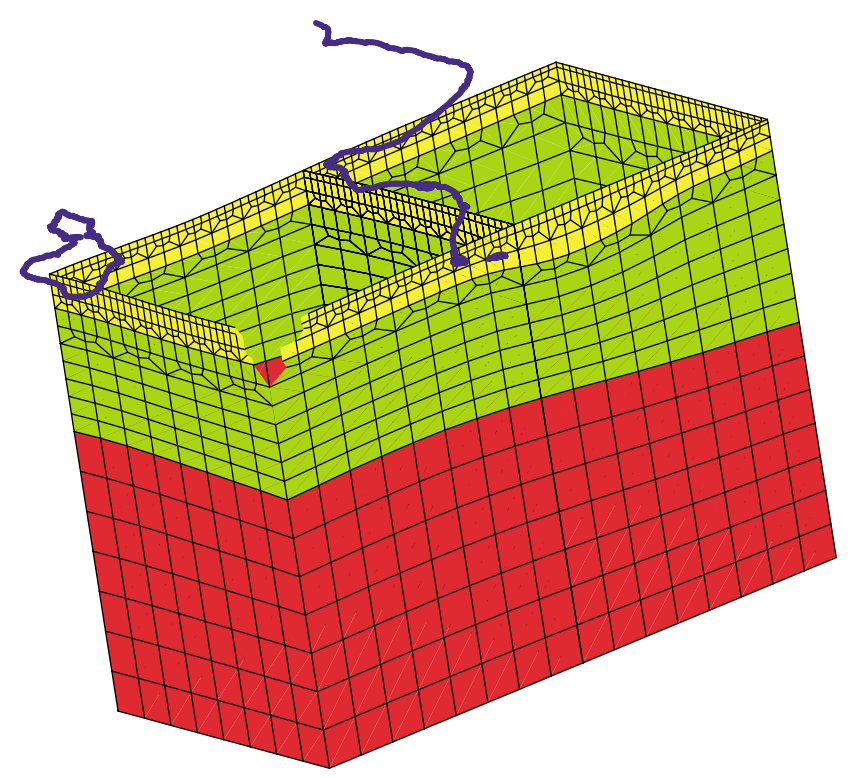

Figure 4. North-south cross section through the mesh of the Los Angeles basin region. For clarity, only the vertical edges of the mesh slices are represented. The blue line shows the Mexican border, the coastline, Palos Verdes, and Santa Catalina Island. The mesh is adapted to the deepest part of the basement surface and to the shape of the Moho taken from Zhu and Kanamori (2000). It is doubled in size twice: first below the low wave-speed surface layer and a second time below the basement. Red represents elements located below the Moho, green elements between the Moho and the bottom of the sedimentary pocket, and yellow elements in the upper part of the model honoring the shape of the surface and the bottom of the sedimentary pocket. Note that for geometrical reasons, we only honor the bottom part of the deep sedimentary pocket (from a depth of $4 \mathrm{~km}$ to a maximum of $8.5 \mathrm{~km}$ ), otherwise we would be unable to mesh the entire structure in regions with very thin (or without) sediments.

In this article, we incorporate $3 \mathrm{D}$ variations in $P$ - and $S$-wave speeds, density, and attenuation. The mesh covers $516 \mathrm{~km} \times 507 \mathrm{~km}$, from $120.3^{\circ} \mathrm{W}$ to $114.7^{\circ} \mathrm{W}$ and from $32.2^{\circ} \mathrm{N}$ to $36.8^{\circ} \mathrm{N}$, incorporates most of the roughly 140 broadband seismographic stations in the TriNet network (www.trinet.org) in southern California, and extends to a depth of $60 \mathrm{~km}$. It is important to honor the major discontinuities in the wave-speed model when creating a mesh of the structure, to avoid numerical diffraction by a staircase discretization of the complex-shaped interfaces (e.g., Zahradník et al., 1993). Therefore, the basin mesh honors the shape of the Moho (Zhu and Kanamori, 2000), the lower part of the sedimentary basin underneath Los Angeles (Süss and Shaw, 2003), as well as topography and bathymetry (USGS, 2003), as illustrated in Figure 4.

In the TriNet network, there are several seismographic stations on the offshore Channel Islands; for this reason the effect of the oceanic water layer is incorporated in the mod- eling based upon an equivalent load formulation that takes into account the weight of the water column (Komatitsch and Tromp, 2002b). This is a long-period approximation that is valid as long as the wavelength of the seismic signals is large compared to the depth of the oceans. The main limitations of such an approximation are discussed in Komatitsch and Tromp (2002b). In the case of the Los Angeles region, we perform simulations at minimum periods of $2 \mathrm{sec}$, that is, the wavelength in the oceans is $2 \times 1500=3000 \mathrm{~m}$, which means that the approximation is valid for shallow oceans, typically with a maximum depth of 500-600 m. Fortunately, this is the case in most parts of the model, as illustrated in Figure 3. Paraxial absorbing conditions (Clayton and Engquist, 1977) are used on the vertical edges and the bottom of the grid to simulate a semi-infinite regional medium. More accurate absorbing boundary conditions, such as the perfectly matched layer (e.g., Bérenger, 1994; Chew and Liu, 1996; Collino and Tsogka, 2001; Komatitsch and Tromp, 2003), could be used instead, but, because we use a large mesh, the simpler paraxial conditions are sufficient.

The method is implemented on a PC cluster computer, a so-called Beowulf machine, using parallel programming based upon a message-passing technique, making use of the message-passing interface (Gropp et al., 1996). To take advantage of the parallel machine architecture, the mesh is divided into 144 slices that are distributed over 144 processors using a regular mesh partitioning topology. The mesh contains 672,768 spectral elements. We use a polynomial degree $N=4$ to sample the wave field; therefore each spectral element contains $(N+1)^{3}=125$ Gauss-Lobatto-Legendre points. Counting points on common spectral-element edges and corners only once, the mesh therefore contains a total of 45.4 million grid points (i.e., 136 million degrees of freedom, because we solve for the three components of displacement at each grid point). The average distance between grid points at the surface is roughly $335 \mathrm{~m}$. One needs to use roughly five points per wavelength to correctly sample the wave field in the SEM (e.g., Seriani and Priolo, 1994); therefore the mesh resolves waves with a shortest period of about $2 \mathrm{sec}$. The calculations require $14 \mathrm{~Gb}$ of distributed memory. On our cluster it takes about $6.5 \mathrm{hr}$ to compute seismograms with a duration of $3 \mathrm{~min}$. We use a timestep of $9 \mathrm{msec}$, that is, a total of 20,000 timesteps.

\section{Validation for a One-Dimensional Model}

In previous work, we carefully benchmarked the SEM against semianalytical solutions for reference Earth models with and without attenuation (Komatitsch and Vilotte, 1998; Komatitsch and Tromp, 1999; Komatitsch et al., 1999; Komatitsch and Tromp, 2002a) and showed its accuracy for modeling seismic-wave propagation. To demonstrate that the nonstructured mesh represented in Figure 4 is efficient for basin models, we study a simple structure consisting of an anelastic layer over a half-space. We use the model shown in Figure 5, which is known as the SCEC/PEER (Pacific 


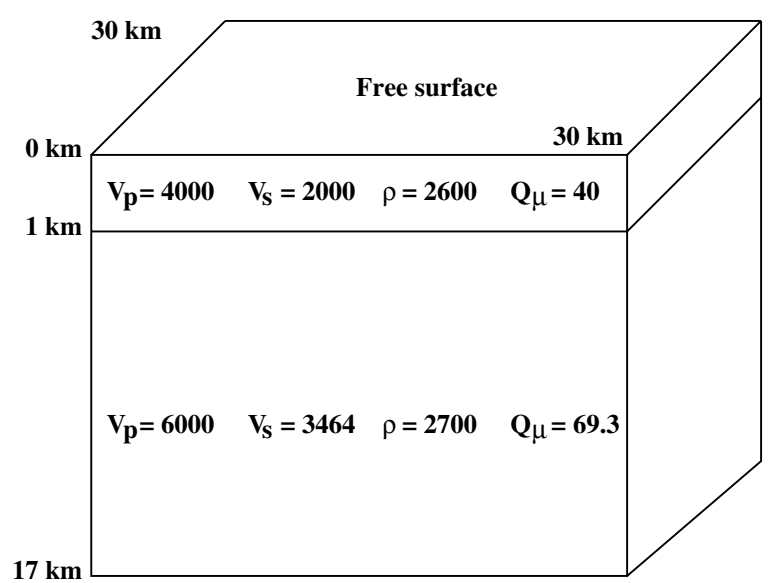

Figure 5. 1D structure used to assess the accuracy of the SEM for an average basin model. The 3D model consists of a layer over a half-space. The horizontal size of the block is $30 \mathrm{~km} \times 30 \mathrm{~km}$, and it extends to a depth of $17 \mathrm{~km}$. This reference model is known as the SCEC/PEER LOH-3 benchmark.

Earthquake Engineering Research Center) LOH-3 benchmark (peer.berkeley.edu). The block has a horizontal size of $30 \mathrm{~km} \times 30 \mathrm{~km}$ and extends to a depth of $17 \mathrm{~km}$. Absorbing conditions are used on all sides of the model except the free surface, in order to simulate a semi-infinite medium. Material properties in the half-space are $V_{\mathrm{p}}=6000 \mathrm{~m} \mathrm{~s}^{-1}, V_{\mathrm{s}}=$ $3464 \mathrm{~m} \mathrm{~s}^{-1}, \rho=2700 \mathrm{~kg} \mathrm{~m}^{-3}$, and a shear quality factor $Q_{\mu}=69.3$ for attenuation. In the layer, $V_{\mathrm{p}}=4000 \mathrm{~m} \mathrm{~s}^{-1}$, $V_{\mathrm{s}}=2000 \mathrm{~m} \mathrm{~s}^{-1}, \rho=2600 \mathrm{~kg} \mathrm{~m}^{-3}$, and $Q_{\mu}=40$. The shear quality factor does not depend on frequency (i.e., the attenuation spectrum is flat). The bulk quality factor $Q_{\kappa}$ is infinite in both regions. Wave speeds $V_{\mathrm{p}}$ and $V_{\mathrm{s}}$ are for a reference frequency of $2.5 \mathrm{~Hz}$. The source is a point dislocation located in the half-space below the layer in the middle of the grid, at a depth of $2 \mathrm{~km}$. The only nonzero component of the moment tensor is $M_{x y}=10^{18} \mathrm{~N} \mathrm{~m}$. The moment-rate time variation of the source is $\left(t / T^{2}\right) \exp (-t / T)$, where $T=$ $0.05 \mathrm{sec}$. The timestep is $\Delta t=3.25 \mathrm{msec}$, and we propagate the signal for $10 \mathrm{sec}$. A receiver is placed at $x=6 \mathrm{~km}$ and $y=8 \mathrm{~km}$, at a horizontal distance of $10 \mathrm{~km}$ from the source, and records the three components of velocity. In Figure 6, we show the results and compare them to a frequency-wavenumber reference solution computed based on a modified version of Apsel and Luco (1983). The two results are almost perfectly superimposed, which allows us to conclude that the method is very accurate for such an average 1D basin model.

\section{Simulations of the 9 September $2001 M_{\mathrm{W}} 4.2$ Hollywood Earthquake}

To assess the quality of the 3D basin model and the 3D SEM simulations, we simulated ground motion for the 9 September $2001 M_{\mathrm{w}} 4.2$ Hollywood earthquake. This event was
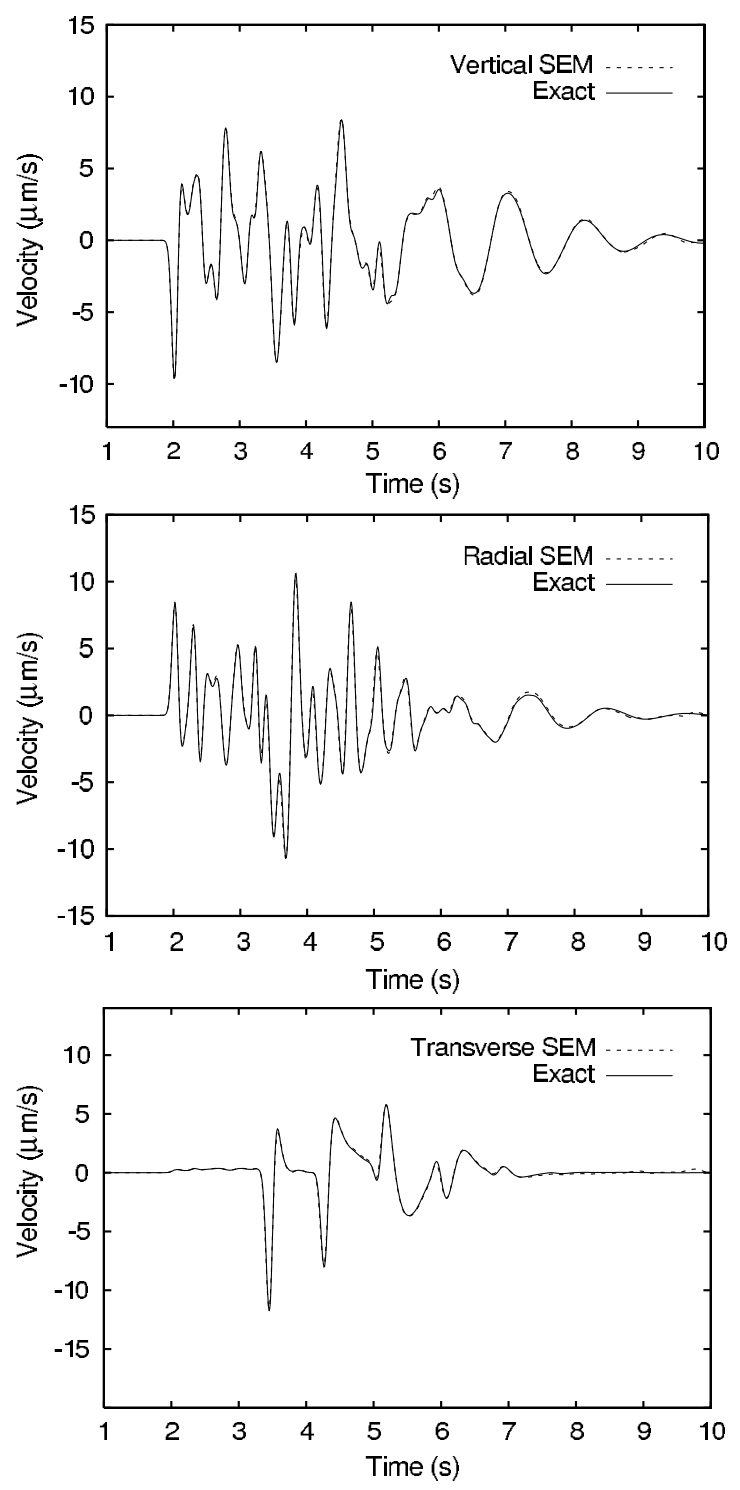

Figure 6. Traces recorded at the surface for the average 1D basin model shown in Figure 5. The source is a point dislocation located in the half-space below the sedimentary layer in the middle of the block at a depth of $2 \mathrm{~km}$. The receiver is located at a horizontal distance of $10 \mathrm{~km}$ from the source. The vertical (top), radial (middle), and transverse (bottom) components of velocity computed using the SEM (dashed line) are compared to the solution computed based upon a modified frequency-wavenumber method (Apsel and Luco [1983], solid line). The two curves are almost perfectly superimposed, which illustrates the accuracy of the SEM, including for surface waves.

located right inside the basin at a depth of approximately $4.5 \mathrm{~km}$ and was well recorded by TriNet; it therefore provides an excellent test of the 3D basin model and the numerical method. Complications associated with source complexity and directivity for larger events (e.g., Wald et al., 1996; Ji et al., 2002) are avoided. To obtain the source mechanism for this event, we performed a 3D centroid moment 
tensor (CMT) inversion based upon the basin model and the SEM. We calculated the required 3D Fréchet derivatives numerically (Liu et al., 2002) by minimizing the waveform misfit between data and synthetic seismograms to obtain the best estimated source parameters. The solution is in excellent agreement with first-motion and surface-wave estimates.

Figure 7 shows snapshots of the simulation. The vertical component of velocity at the surface is represented. If the basin model were 1D, one would see concentric circles centered on the epicenter. The highly distorted wave fronts are due to substantial 3D variations in the model. Note that energy gets trapped in the Los Angeles and San Fernando basins due to the low wave-speed sediments. This is particularly clear between 63.8 and $85.4 \mathrm{sec}$, where ground motion lasts much longer in the basin than in the surrounding mountains and in the Palos Verdes peninsula.

In Figure 8 we compare the results of 3D SEM simulations to three-component displacement data recorded by TriNet stations. Both data and synthetic seismograms are bandpass filtered between 6 and $35 \mathrm{sec}$ with a four-pole twopass Butterworth filter. We focus our attention on the Los Angeles region, where the detailed Harvard basin model is defined and in which the event took place. Notice that at these periods we can fit the data very well on all three components. The model captures the amplifications and resonance associated with the Los Angeles basin, for example, transverse components at LAF, STS, LGB, and PDR and radial components are PDR, WTT, and LLS. Notice that stations in the San Gabriel mountains (e.g., CHF, BFS, TA2, and MWC) have relatively small displacements on all three components that are well fit by the synthetic seismograms. The good fit to the data demonstrates that the SEM wavefront distortions in Figure 7 capture actual facets of the data. Because the model is a $P$-wave speed model and the largest signals in the seismograms are surface waves predominantly sensitive to $S$-wave speed, we allow for a small station correction in our SEM simulations. This stems from the fact that the $S$-wave speed $\left(V_{\mathrm{s}}\right)$ model is based upon a simple scaling relation to $P$-wave speed $\left(V_{\mathrm{p}}\right)$. Currently, for simplicity, rather than trying to determine an optimal scaling relation or an independent $S$-wave speed model, we choose to use such a simple scaling, but allow for deficiencies in the $V_{\mathrm{s}}$ model by introducing a station correction. To find the station correction, we calculate the cross correlation between the data and the synthetic seismograms and use this to determine the phase shift between the data and synthetic seismograms as well as the associated amplitude anomaly. In Figure 9 we plot the value of the cross correlation, the time shift, and the associated amplitude anomaly. Note that the corrections are generally small, typically less than plus or minus $2 \mathrm{sec}$ for stations within $200 \mathrm{~km}$ of the epicenter. This can only be a temporary solution, and future work will have to focus on building an independent $V_{\mathrm{s}}$ model. We plan to use these station corrections to invert for an improved $V_{\mathrm{s}}$ model, and once this new model is defined, we will no longer use these station corrections.
Figure 10 illustrates that even at periods between 2 and $35 \mathrm{sec}$, we can fit the data reasonably well on all three components. Figure 11 shows peak ground displacement, velocity, and acceleration. Notice the amplifications in ground velocity and acceleration in the San Fernando Valley toward the north, in particular near its eastern edge. A hard-rock site, such as Palos Verdes along the coast, shows no significant amplification. The same is true in the mountains, most of the energy being trapped in the two basins. Maps such as these can be used to construct synthetic ShakeMaps that would complement the empirically derived ShakeMaps depicting the intensity of ground motion produced automatically by the USGS (www.trinet.org/shake).

\section{Simulations of the 3 September $2002 M_{\mathrm{W}} 4.2$ Yorba Linda Earthquake}

Next, we simulate ground motion for a second event, the 3 September $2003 M_{\mathrm{w}} 4.2$ Yorba Linda earthquake, which occurred at a depth of $7 \mathrm{~km}$. Again we performed a 3D CMT inversion for this event, which is in excellent agreement with first-motion and long-period surface-wave mechanisms. Figure 12 illustrates that for this event we can also fit the data very well at periods between 6 and $35 \mathrm{sec}$. We show the transverse component of displacement for stations in the Los Angeles area. To illustrate the magnitude of the basin resonance, in Figure 13 we show the same transverse component displacement data compared to SEM synthetic seismograms for the 1D southern California background regional model of Dreger and Helmberger (1990). Note that at basin sites, such as LAF and BRE, the observed amplitudes can be 20 times larger than the 1D predictions, even at long periods. Of course one could attempt to determine the best 1D model for each event-station pair, but this figure illustrates that such models are meaningless because of very large local variations in their response pattern. For example, stations BRE, STS, and RPV trend along the same direction, and yet they have entirely different responses. Note from Figure 12 that the 3D model captures all three stations very nicely. We note that the 1D model of Dreger and Helmberger (1990) was developed to fit regional long-period waveforms, not basin sites.

Figure 14 shows peak ground displacement, velocity, and acceleration for this event. Note that, as for the Hollywood event of Figure 11, the peak ground velocity and acceleration maps are similar in character but that the peak ground displacement map is smoother in nature.

\section{Discussion}

Our analyses of the Hollywood and Yorba Linda earthquakes demonstrate that it is feasible to fit three-component seismic data accurately down to a period of $2 \mathrm{sec}$ inside the basin model and $6 \mathrm{sec}$ in the regional model, thereby validating the basin model of Süss and Shaw (2003) and the SEM. Signals with a very wide dynamic range are well cap- 

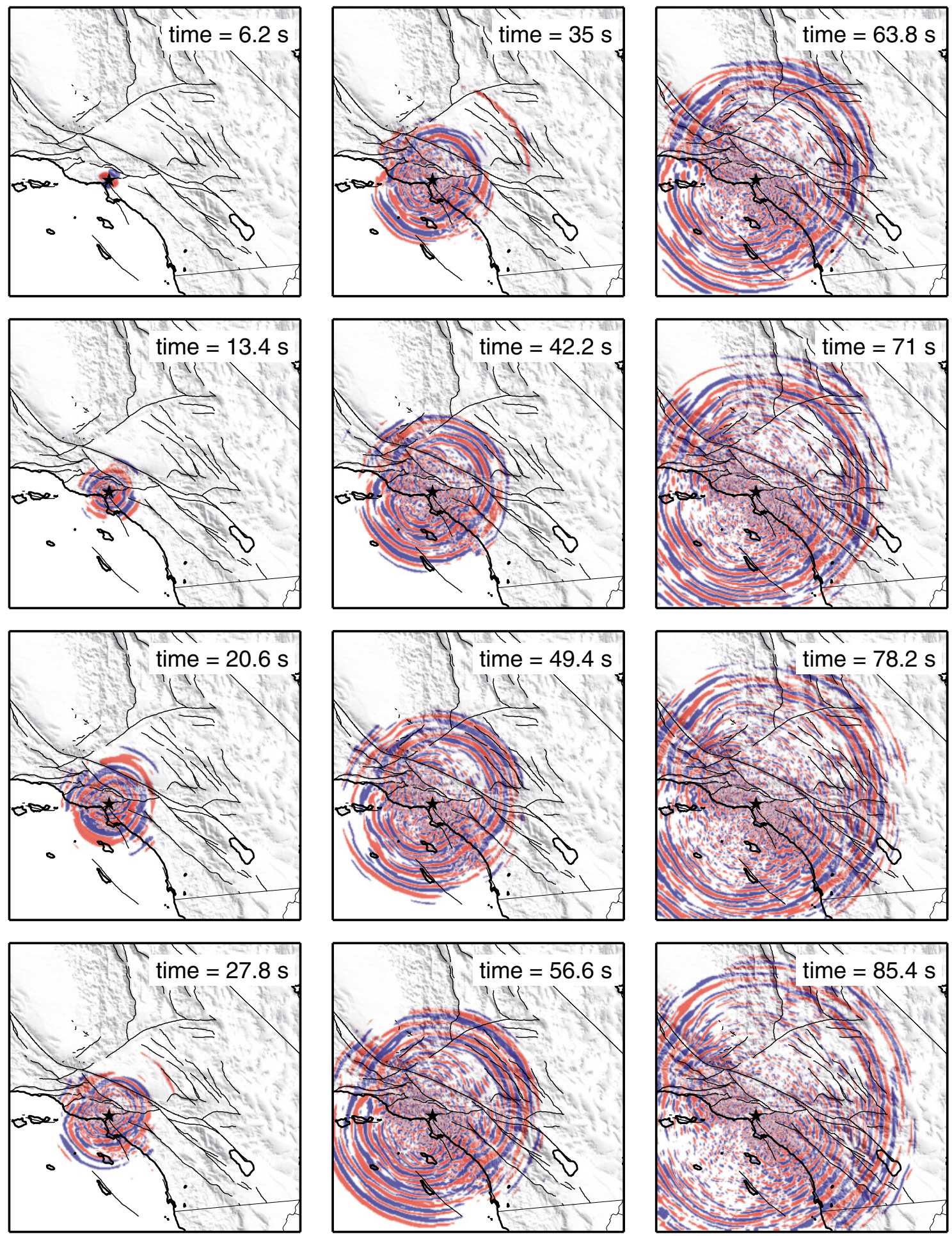

Figure 7. Snapshots of the wave field simulated for the 9 September $2001 M_{\mathrm{w}} 4.2$ Hollywood earthquake. The vertical component of velocity is displayed, with red colors denoting positive values and blue negative values. In a 1D model the wave field would consist of concentric circles centered on the epicenter. The wavefront distortions are due to the presence of low wave-speed sediments in the Los Angeles and San Fernando sedimentary basins. Note in particular how ground motion lasts much longer in and around the basin, where energy is trapped because of the presence of sediments. This is particularly clear between 63.8 and $85.4 \mathrm{sec}$, where ground motion lasts much longer in the basin than in the surrounding mountains and in the Palos Verdes peninsula. 

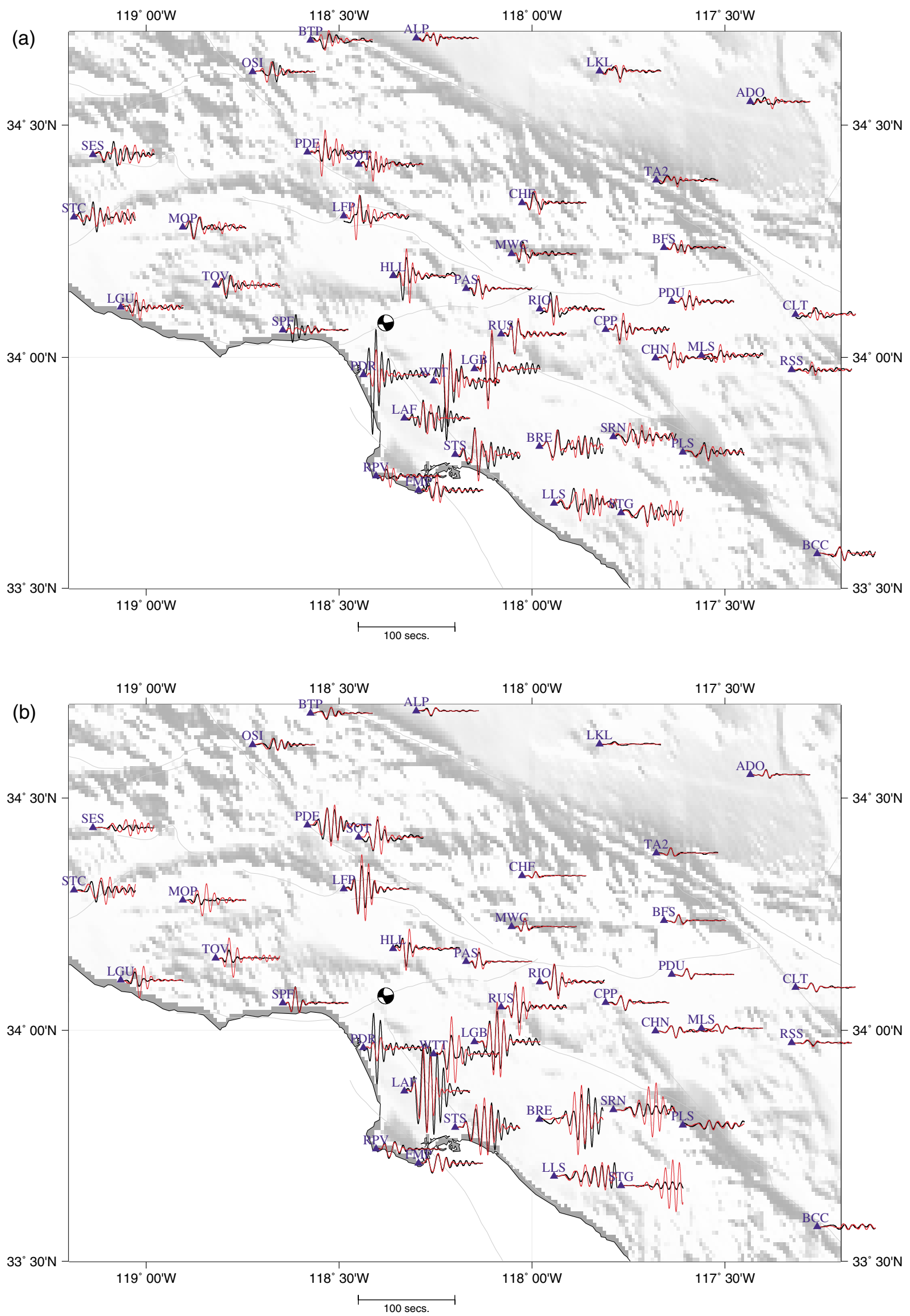

Figure 8. Caption on next page. 


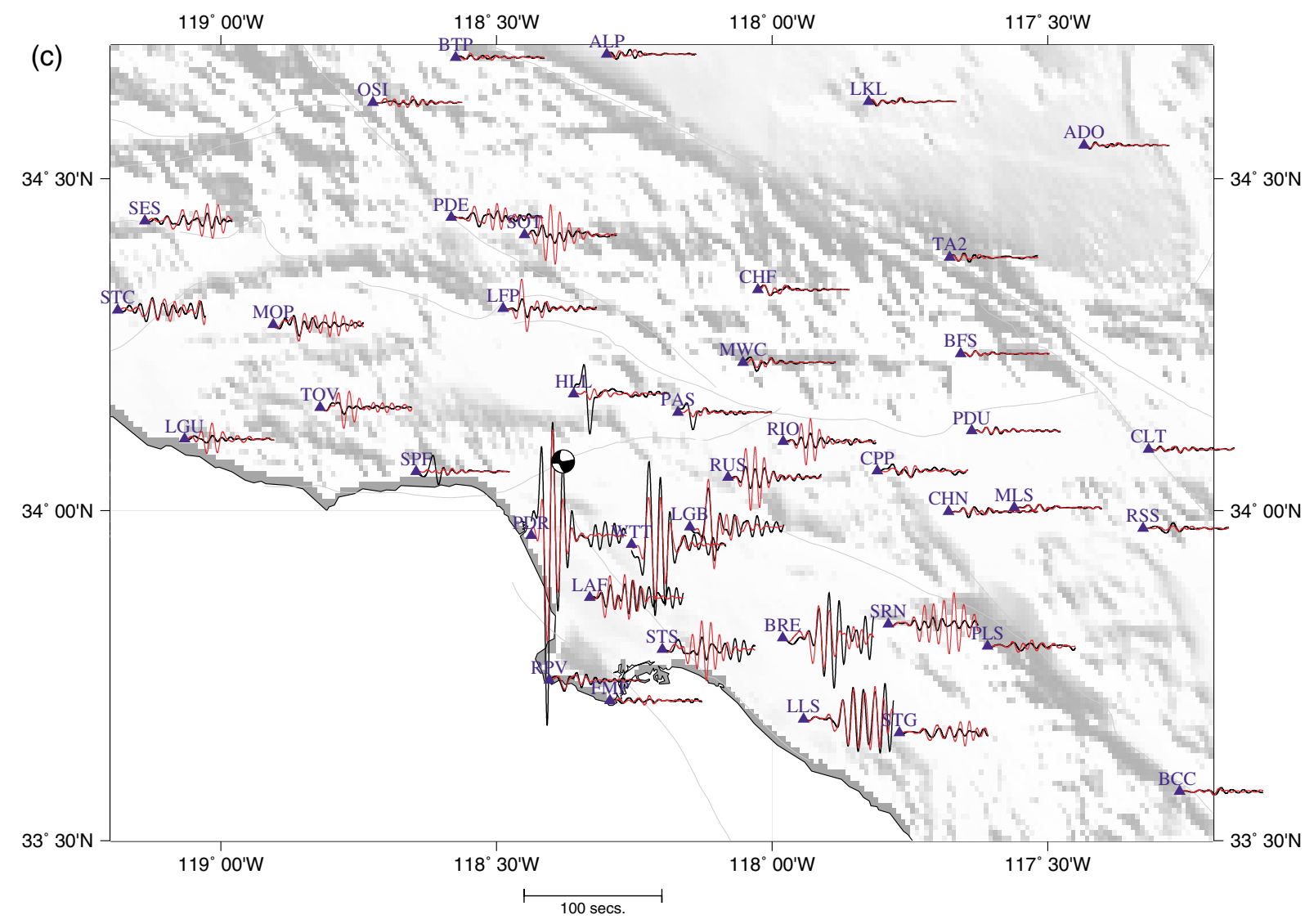

Figure 8. Data (black) and 3D SEM synthetic seismograms (red) for the 9 September, 2001, Hollywood event are plotted on a map of the Los Angeles area. The mechanism and location of the event are indicated by the black-and-white beach ball. The timescale is indicated by the scale bar at the bottom. (a) Vertical component, (b) transverse component, and (c) radial component. Stations are denoted by blue triangles and labeled by their station codes. The instrument response was deconvolved from the data to obtain ground displacement. Both the data and the synthetic seismograms were subsequently bandpass filtered between 6 and $35 \mathrm{sec}$ with a four-pole two-pass Butterworth filter.

tured by the model, and, in particular, stations within the Los Angeles and San Fernado basins are fit well on all three components. The full complexity of the $3 \mathrm{D}$ model is included in the simulations, that is, the effect of constant attenuation, topography/bathymetry, and the oceans. Topography and attenuation in particular have a significant effect on wave propagation, as illustrated in Figure 15.

There are, however, some limitations to the model. Figure 16 illustrates that in the Salton Sea area, for instance at stations SAL, ERR, and WES, and at shorter periods in the Mojave Desert, for instance, at station ADO, there is substantial low wave-speed sediment cover that is not included in our model. This causes resonance in the data that is not correctly reproduced. As can be seen in Figure 1, this region is not covered by our basin model, but rather by the regional model of Hauksson (2000). These deficiencies in the background model can be addressed by incorporating low wavespeed layers in selected areas and by expanding our highresolution model to encompass these problematic areas.
Another issue is the fact that the geotechnical layer, that is, the first tens of meters of sediments, which are highly heterogeneous and often significantly modify ground motion and local amplification (e.g., Anderson et al., 1996), is currently not included in our basin model. This layer will be incorporated in a future version of the model. However, it will be difficult to take into account in our numerical simulations, due to the very low $S$-wave speeds that are involved, which require a very fine grid. Using our current mesh, we are limited to minimum $S$-wave speeds of about $670 \mathrm{~m} \mathrm{~s}^{-1}$. (Our simulations are designed to be accurate down to a period of $2 \mathrm{sec}$, the grid spacing at the surface is $335 \mathrm{~m}$, and in the SEM one needs to sample the wave field using approximately five points per minimum wavelength, as mentioned previously.)

An additional difficulty in basin simulations is the lack of detailed knowledge of attenuation. We have used a constant shear quality factor $Q_{\mu}=90$ in the sediments, no bulk $Q$, and no attenuation in the bedrock; this model is, of 

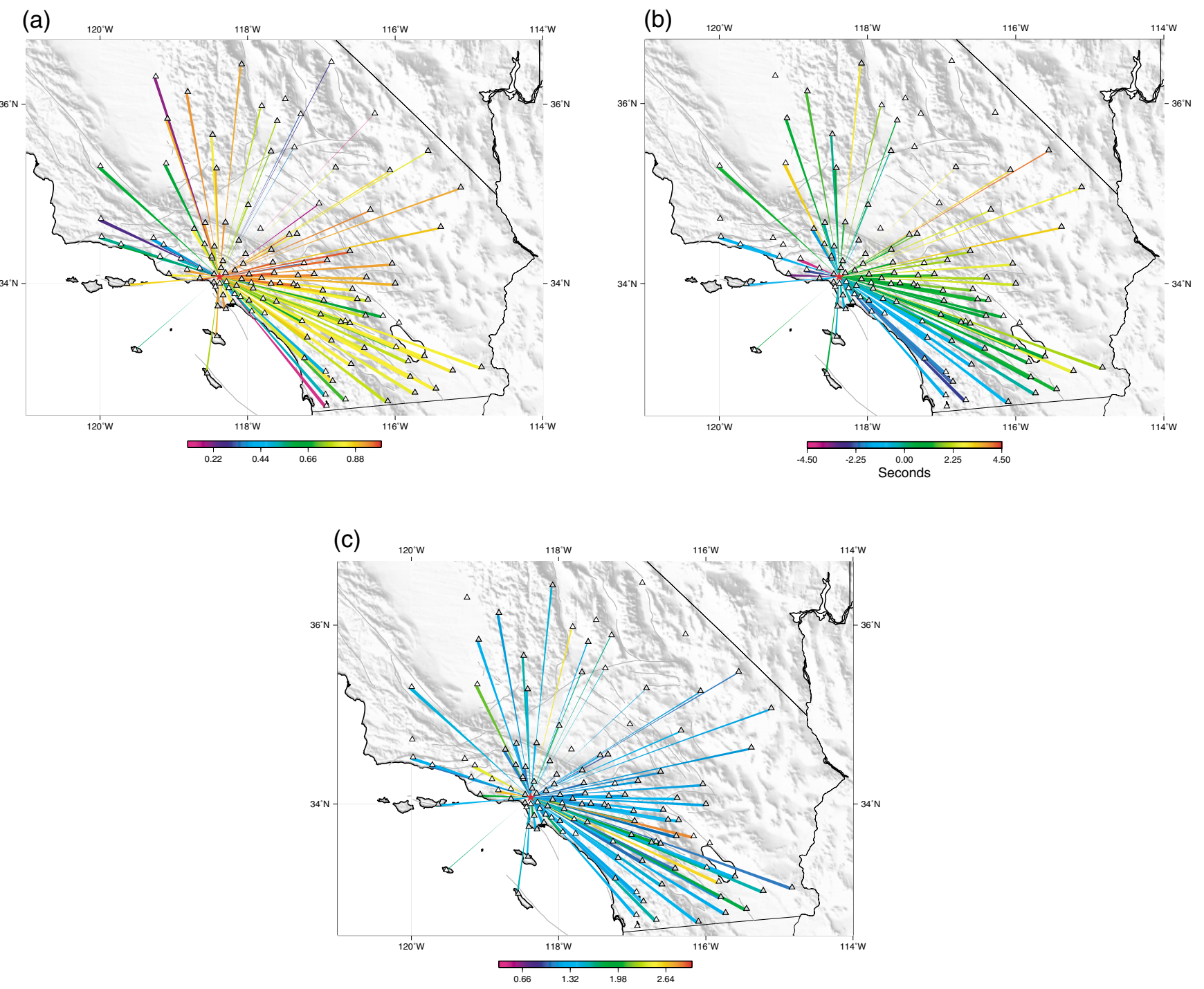

Figure 9. We use cross correlation to determine the time shift between the data and the SEM synthetic seismograms. We show the results for the transverse component of displacement for the Hollywood event bandpass filtered between 6 and $35 \mathrm{sec}$ with a four-pole two-pass Butterworth filter. (a) Correlation between the data and synthetic seismograms. Color-coded lines between eventstation pairs indicate the correlation coefficients, with red denoting the highest correlations and blue lower correlations. The stations selected for this figure have a correlation coefficient of 0.1 or larger. (b) Time shifts are plotted as color-coded lines between event-station pairs and are typically between +2 and $-2 \mathrm{sec}$. A positive (red) anomaly indicates that the synthetic seismograms are faster than the data, whereas negative (blue) values indicate that the synthetic seismograms arrive slower than the data. The stations selected for this figure have a time shift smaller than $4.5 \mathrm{sec}$ and a correlation coefficient greater than 0.4. (c) Amplitude anomalies between the data and 3D SEM synthetic seismograms. Color-coded lines between event-station pairs indicate the amplitude ratio between data and synthetic seismograms. An amplitude ratio greater than 1 (red) indicates the SEM amplitude is larger than the data, whereas a ratio smaller than 1 (blue) denotes SEM amplitudes smaller than the data. These amplitude anomalies are due to effects related to focusing and defocusing, attenuation, and the source. The stations selected for this figure have an amplitude ratio smaller than $3.0 \mathrm{sec}$ and a correlation coefficient greater than 0.3 .

course, not realistic. However, it is difficult to improve, because very few available data sets constrain attenuation. Olsen et al. (2003) recently started to address this issue based upon 3D finite-difference numerical simulations for the SCEC-II Los Angeles basin model (Magistrale et al., 2000).
With present-day computer hardware, it is technically feasible to simulate ground motion for a given wave-speed model at much higher frequencies (at least $2 \mathrm{~Hz}$ or more). As is often the case in regional or local seismology (e.g., Graves, 1999), we are presently limited by our knowledge 


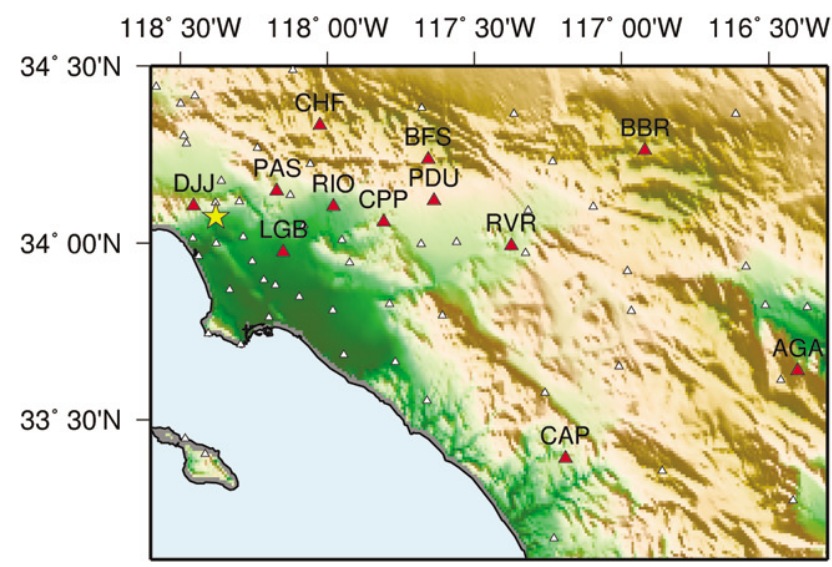

September $9,2001 \mathrm{M}_{\mathrm{w}}=4.2$

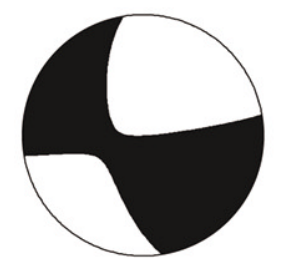

data

3D synthetics

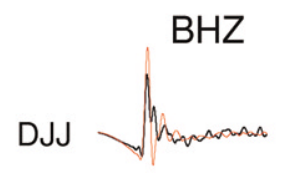<smiles>CC1=CC(C)=C(C)C1C</smiles><smiles>[B]C1CC1CCC</smiles>

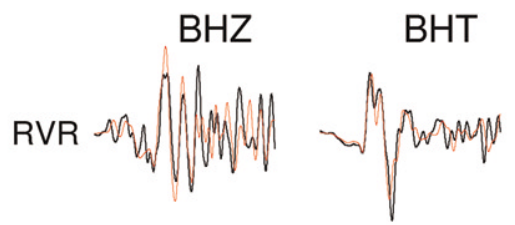

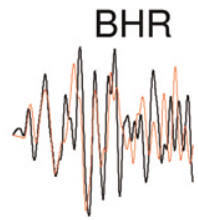<smiles>Cc1ccc([AsH])cc1S</smiles>

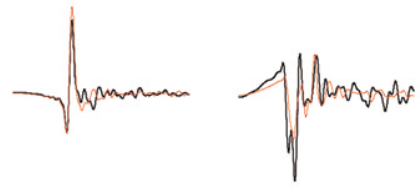

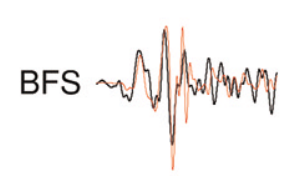

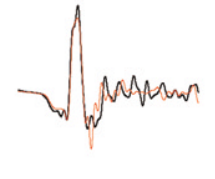

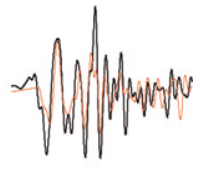

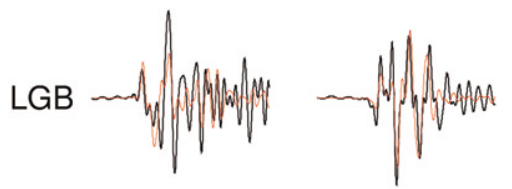<smiles>CCC(C)C</smiles>

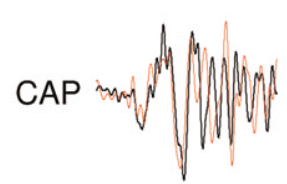

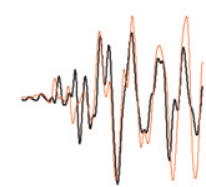

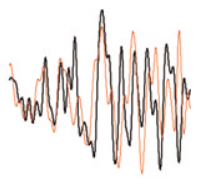

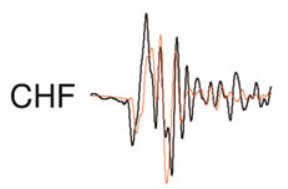<smiles>CC#CCCCC</smiles><smiles>C#CC(C)C#CC(C)C</smiles>

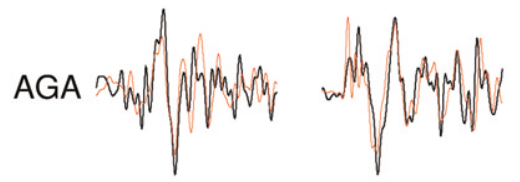

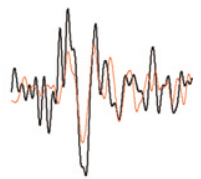<smiles>[R]OCc1ccccc1I</smiles><smiles>C#CC(C)CCCCCC</smiles><smiles>C[Si](C)(C)[Si](C)(C)C</smiles>

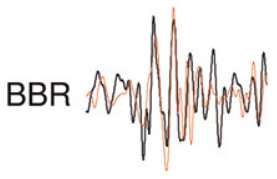<smiles>CCC1CCC(C)CC1C</smiles>

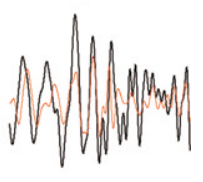

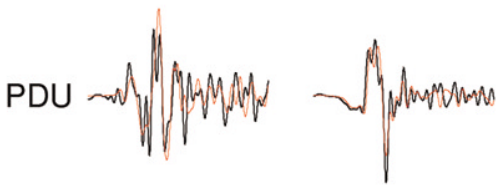
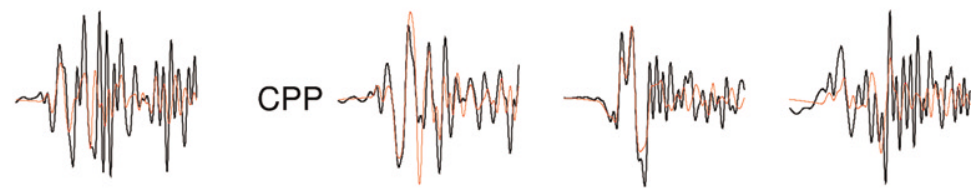

$20 \mathrm{~s}$

Figure 10. (Top left) Map showing the epicenter (yellow star) and stations (red triangles with black labels) for which data and synthetic seismograms bandpass filtered between 2 and $35 \mathrm{sec}$ with a four-pole two-pass Butterworth filter are plotted in the bottom panel. The source mechanism of the 9 September $2001 M_{\mathrm{w}} 4.2$ Hollywood earthquake is shown in the top right. Vertical (left columns), transverse (middle columns), and radial (right columns) components of displacement at 12 stations are shown in the bottom panel. SEM results are in red and data in black. The timescale is indicated by the scale bar at the bottom. Amplitudes are normalized independently at each station. We selected 12 among the stations where the best fit is obtained. Fit is determined by calculating the cross correlation and the amplitude difference between data and synthetic seismograms. 
(a)

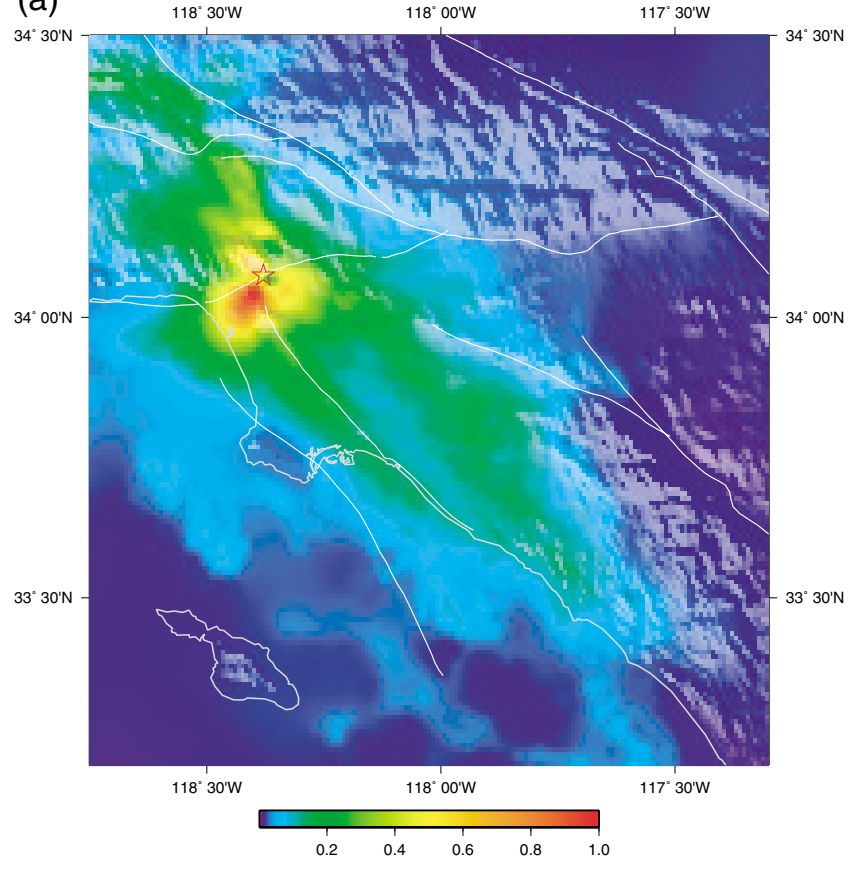

(b)

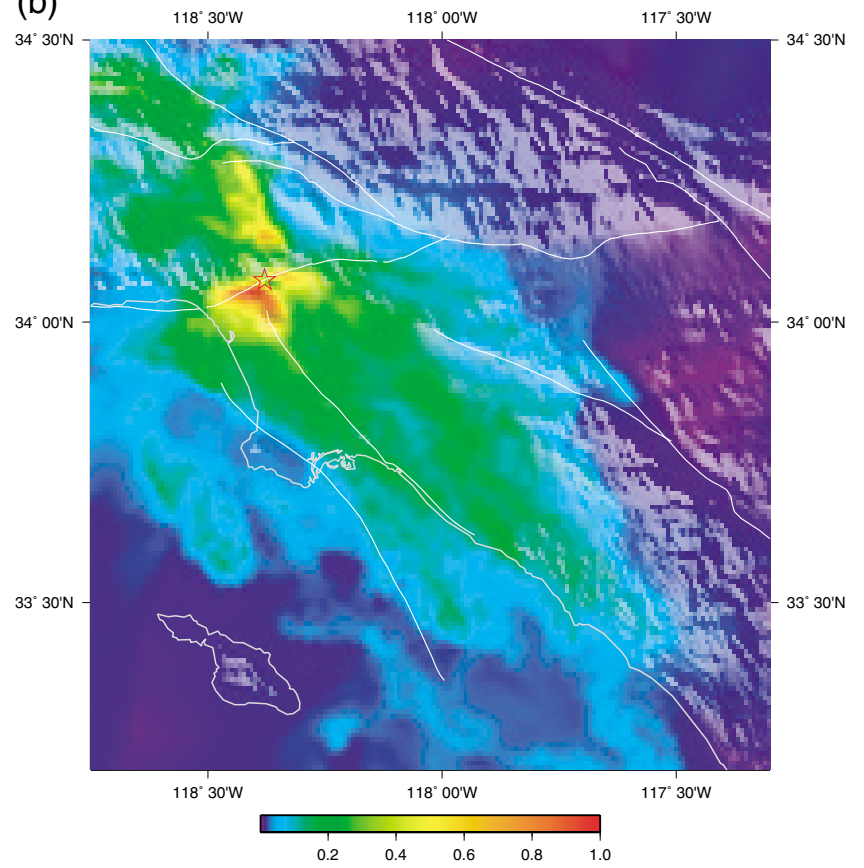

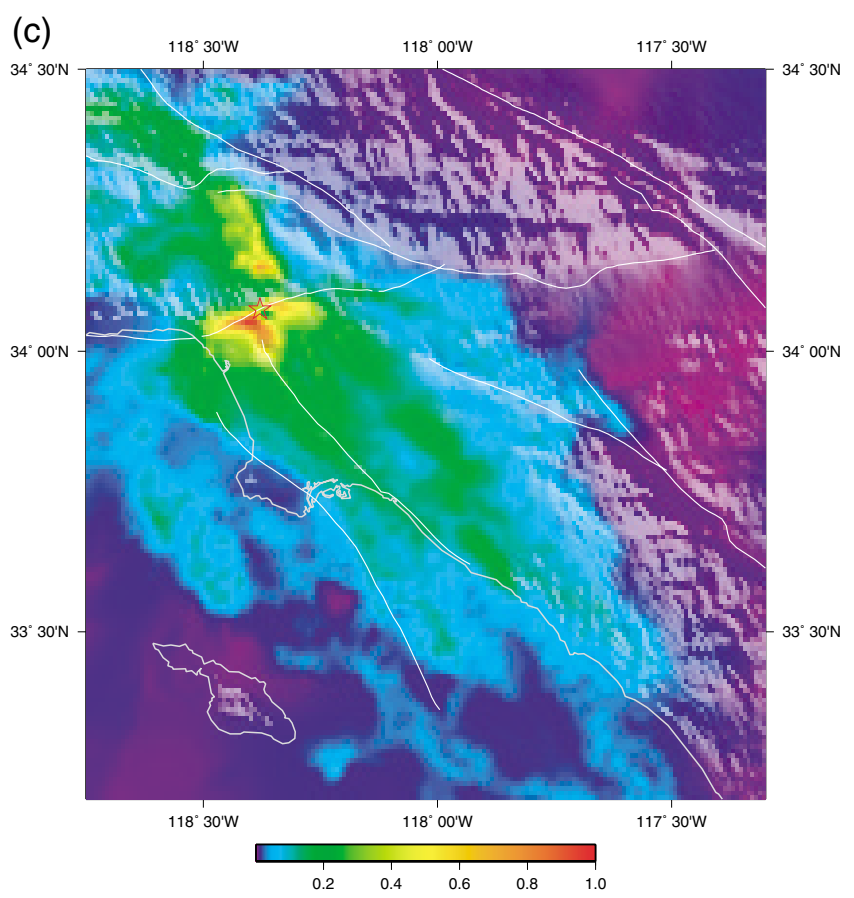

Figure 11. Peak ground displacement (a), velocity (b), and acceleration (c) for the Hollywood earthquake. Shown is a close-up on the Los Angeles basin. A value of 1 on the color scale corresponds to maxima of $0.80 \mathrm{~mm}, 0.92 \mathrm{~mm} \mathrm{~s}^{-1}$ and $2.15 \mathrm{~mm} \mathrm{~s}^{-2}$ for the norm of displacement, velocity, and acceleration at the surface, respectively. One can notice that amplification occurs in the basin, where most of the energy is trapped, while hard-rock sites such as Palos Verdes, or the mountains surrounding the Los Angeles and San Fernando basins, show little acceleration. Significant amplification occurs in the San Fernando valley, north of the epicenter, in particular near its eastern edge. Note that the peak ground velocity and acceleration maps are similar in character, while the peak ground displacement map is smoother in nature. 


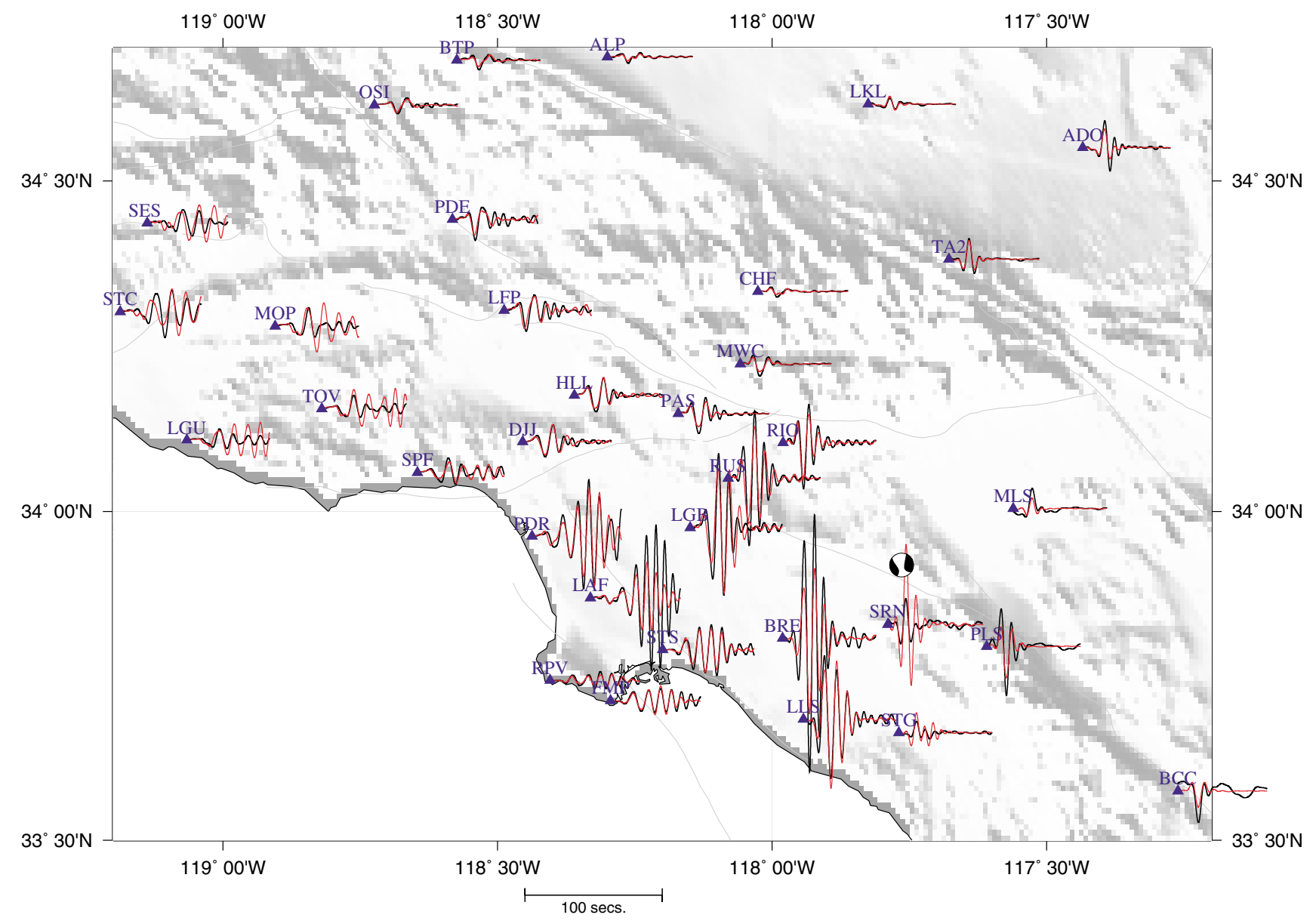

Figure 12. Transverse component data (black) and 3D SEM synthetic seismograms (red) for the 3 September 2002 Yorba Linda event are plotted on a map of the Los Angeles area. Stations are denoted by blue triangles and labeled by their station codes. The instrument response was deconvolved from the data to obtain ground displacement. Both the data and the synthetic seismograms were subsequently bandpass filtered between 6 and $35 \mathrm{sec}$ with a four-pole two-pass Butterworth filter. The mechanism and location of the event are indicated by the black-and-white beach ball. The timescale is indicated by the scale bar at the bottom.

of the 3D model, not by the accuracy or the cost of the calculations. Our current basin model is largely based upon $P$-wave speed information. Ground motions in the basin are to a large extent determined by $S$-wave speeds, which we estimate based upon a simple scaling relationship. Therefore, the basin model could be improved by adding constraints on the $S$-wave speed and density structure, for instance based upon borehole data (Stidham et al., 2001), as well as more precise $P$-wave speed constraints in subregions of the model. In a related effort, we are planning to use surface-wave phase delays, such as those shown in Figure 9, as the starting point for an inversion for an improved $S$-wave model.

Because we are trying to fit signals in both amplitude and phase, it is crucial that instruments are properly calibrated, in particular in terms of timing, and that their orientation is precisely known. Otherwise, the inversion of amplitude anomalies could be compromised by uncertainties related to station parameters.

\section{Conclusions and Perspectives}

We have demonstrated that ground motion in the Los Angeles basin can be modeled accurately based upon a recently developed basin model and a very precise numerical technique. The basin model is constrained by hundreds of petroleum-industry well logs and more than $20,000 \mathrm{~km}$ of seismic reflection profiles. The numerical simulations are based upon the SEM, which accounts for 3D variations of seismic-wave speeds and density, topography and bathymetry, and attenuation. They demonstrate that it is feasible to predict ground motion at periods longer than $2 \mathrm{sec}$ using realistically complex models, thus improving our ability to assess seismic hazard. Peak ground displacement, velocity, and acceleration maps clearly illustrate that large amplification occurs within the basin.

Making use of the basin model in combination with the SEM allows one to invert for earthquake source parameters 


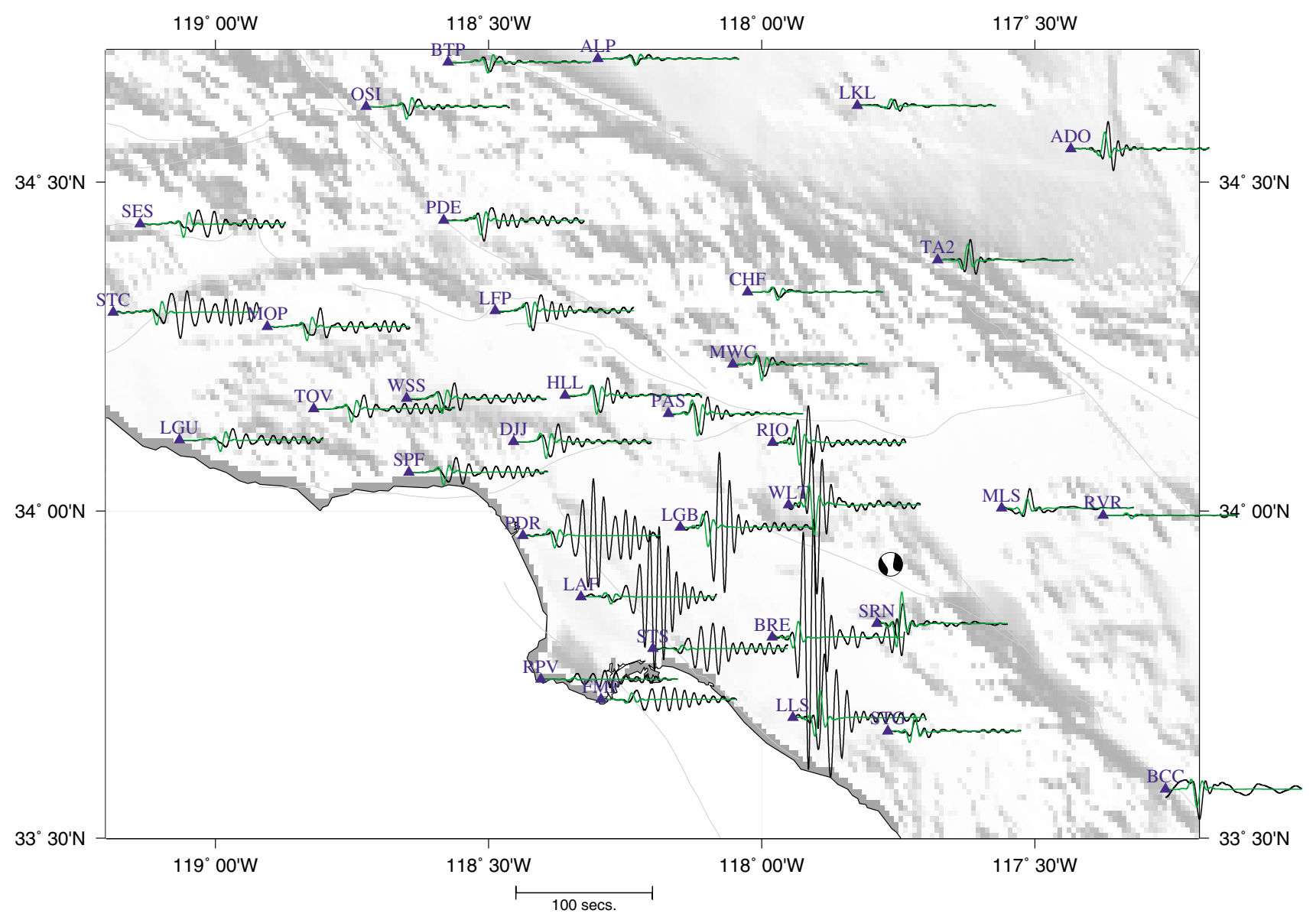

Figure 13. Transverse component data (black) and 1D SEM synthetic seismograms (green) for the 3 September 2002 Yorba Linda event are plotted on a map of the Los Angeles area. The background regional 1D model is that of Dreger and Helmberger (1990). Stations are denoted by blue triangles and labeled by their station codes. The instrument response was deconvolved from the data to obtain ground displacement. Both the data and the synthetic seismograms were subsequently bandpass filtered between 6 and $35 \mathrm{sec}$ with a four-pole two-pass Butterworth filter. The mechanism and location of the event are indicated by the black-and-white beach ball. The timescale is indicated by the scale bar at the bottom. Attenuation was not included in this 1D calculation.

by numerically calculating the necessary Fréchet derivatives (Liu et al., 2002) and obtaining the estimated source parameters by minimizing the waveform misfit between the data and synthetic seismograms. Since a CMT inversion involves of order 10 model parameters, the required simulations can be done easily from a computational perspective. Our intent is to start performing CMT inversions routinely for all wellrecorded future and past events above a certain magnitude threshold. The resulting catalog of regional 3D CMT solutions should be very useful to the community and would complement existing catalogs based upon first-motion studies and long-period surface waves.

An important future goal is to assess seismic risk for hypothetical large events by performing parametric studies for a number of earthquake scenarios. In this article, we have used two small events to validate the basin model and the numerical technique, while avoiding difficulties related to finite-size sources and rupture velocity models for larger events. However, the SEM is not limited to point sources: a finite-size source can be used by summing individual contributions from points located along the fault plane. This approach can be used to calculate synthetic peak ground displacement, velocity, and acceleration maps, such as those in Figures 11 and 14, to assess seismic hazards associated with such large events.

\section{Acknowledgments}

The authors would like to thank Egill Hauksson and Jascha Polet for first-motion and surface-wave centroid moment tensor estimates, Hiroo Kanamori for fruitful discussion, Steven M. Day for the analytical solution of the SCEC LOH.3 benchmark, and TriNet for access to the data. They 

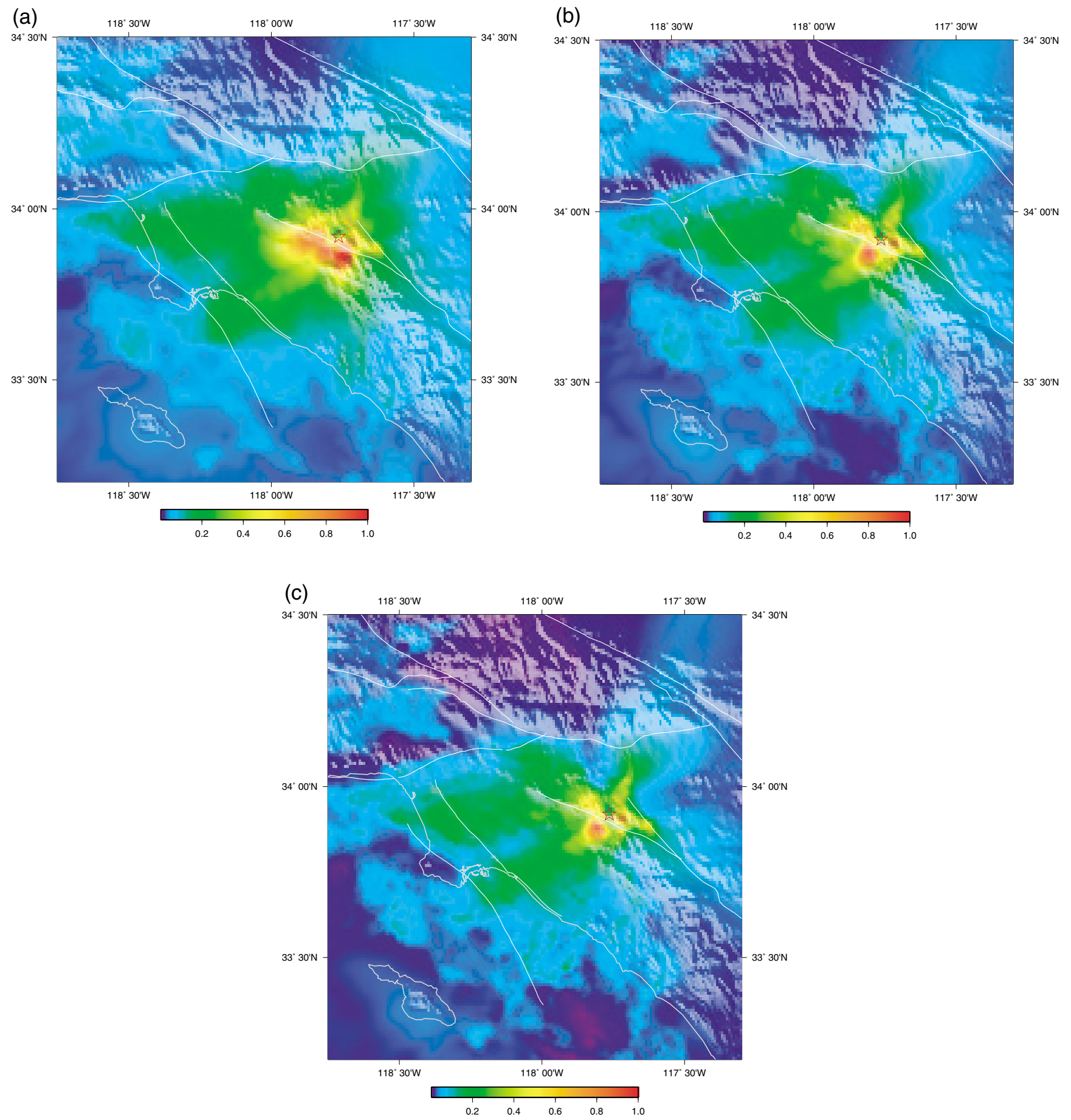

Figure 14. Peak ground displacement (a), velocity (b), and acceleration (c) for the Yorba Linda earthquake. A value of 1 corresponds to maxima of $0.64 \mathrm{~mm}, 0.94 \mathrm{~mm} \mathrm{~s}^{-1}$ and $2.02 \mathrm{~mm} \mathrm{~s}^{-2}$ for the norm of displacement, velocity, and acceleration at the surface, respectively. Note that, as for the Hollywood event in Figure 11, the peak ground velocity and acceleration maps are similar in character, but that the peak ground displacement map is smoother in nature. Again, hard-rock sites such as Palos Verdes and the mountains exhibit less amplification. 
(a)

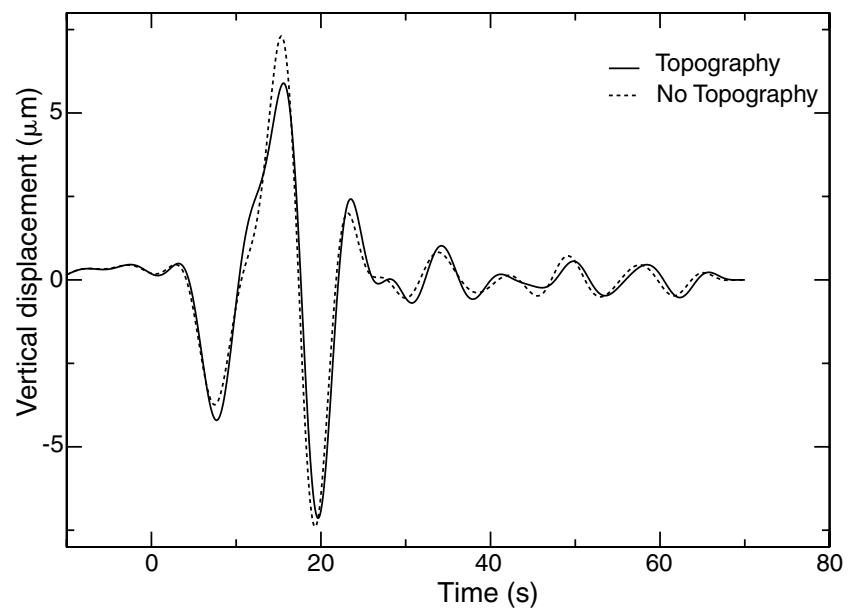

(b)

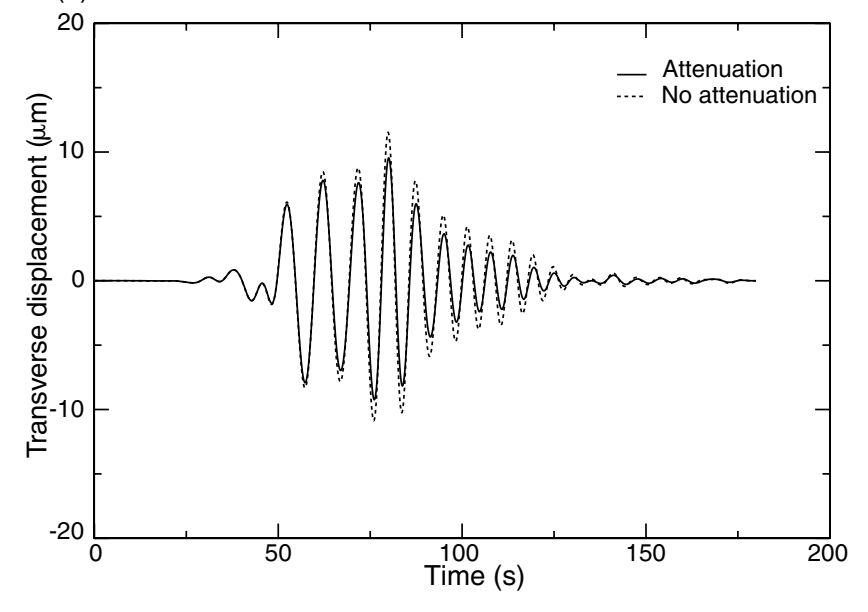

Figure 15. (a) Vertical component displacement SEM synthetic seismogram for the Yorba Linda earthquake recorded at MWC (Mount Wilson) when topography is included in the 3D simulations (solid line) and when a flat free surface is used (dashed line). (b) Transverse component for the Hollywood earthquake at station CAP (Capra Ranch) with (solid line) and without (dashed line) attenuation. The results are filtered between 6 and $35 \mathrm{sec}$ with a four-pole two-pass Butterworth filter. These seismograms clearly show that the effect of topography and attenuation on seismic-wave propagation in the basin is not negligible.

also thank Thomas Pratt and an anonymous reviewer for comments that improved the manuscript. This research was funded in part by the National Science Foundation and by the National Earthquake Hazard Reduction Program under Grant 99HQGR001. This is Contribution Number 8966 of the Division of Geological and Planetary Sciences, California Institute of Technology.

\section{References}

Aagaard, B. T., J. F. Hall, and T. H. Heaton (2001). Characterization of near-source ground motions with earthquake simulations, Earthquake Spectra 17, no. 2, 177-207.

Alex, C. M., and K. B. Olsen (1998). Lens effect in Santa Monica? Geophys. Res. Lett. 25, 3441-3444.

Anderson, J. G., Y. Lee, Y. Zeng, and S. M. Day (1996). Control of strong motion by the upper 30 meters, Bull. Seism. Soc. Am. 86, 1749-1759.

Antolik, M., S. Larsen, D. Dreger, and B. Romanowicz (1996). Modeling broadband waveforms in central California using finite differences, Seism. Res. Lett. 67, 30.

Apsel, R. J., and J. E. Luco (1983). On the Green's functions for a layered half-space, Bull. Seism. Soc. Am. 73, 931-951.

Bao, H., J. Bielak, O. Ghattas, L. F. Kallivokas, D. R. O'Hallaron, J. R. Shewchuk, and J. Xu (1998). Large-scale simulation of elastic wave propagation in heterogeneous media on parallel computers, Comput. Methods Appl. Mech. Eng. 152, 85-102.

Bérenger, J. P. (1994). A perfectly matched layer for the absorption of electromagnetic waves, J. Comput. Phys. 114, 185-200.

Bielak, J., J. Xu, and O. Ghattas (1999). Earthquake ground motion and structural response in alluvial valleys, J. Geotech. Geoenv. Eng. 125, 413-423.

Boore, D. M. (1972). Finite difference methods for seismic wave propagation in heterogeneous materials, in Methods in Computational Physics, Vol. 11, Academic, New York.

Bouchon, M., and J. S. Barker (1996). Seismic response of a hill: the example of Tarzana, California, Bull. Seism. Soc. Am. 86, no. 1A, 66-72.
Capdeville, Y., E. Chaljub, J. P. Vilotte, and J. P. Montagner (2003). Coupling the spectral element method with a modal solution for elastic wave propagation in global Earth models, Geophys. J. Int. 152, 34-67.

Carcione, J. M., and P. J. Wang (1993). A Chebyshev collocation method for the wave equation in generalized coordinates, Comp. Fluid Dyn. J. 2, 269-290.

Catchings, R. D., and W. H. K. Lee (1996). Shallow velocity structure and Poisson's ratio at the Tarzana, California, strong-motion accelerometer site, Bull. Seism. Soc. Am. 86, 1704-1713.

Chaljub, E. (2000). Modélisation numérique de la propagation d'ondes sismiques en géométrie sphérique: application à la sismologie globale (Numerical modeling of the propagation of seismic waves in spherical geometry: applications to global seismology), Ph.D. thesis, Université Paris VII Denis Diderot, Paris, France.

Chaljub, E., Y. Capdeville, and J. P. Vilotte (2003). Solving elastodynamics in a fluid-solid heterogeneous sphere: a parallel spectral element approximation on non-conforming grids, J. Comput. Phys. 187, no. 2, $457-491$.

Chew, W. C., and Q. Liu (1996). Perfectly matched layers for elastodynamics: a new absorbing boundary condition, J. Comput. Acoust. 4, no. 4, 341-359.

Clayton, R., and B. Engquist (1977). Absorbing boundary conditions for acoustic and elastic wave equations, Bull. Seism. Soc. Am. 67, 15291540.

Cohen, G., P. Joly, and N. Tordjman (1993). Construction and analysis of higher-order finite elements with mass lumping for the wave equation, in Proc. of the Second International Conference on Mathematical and Numerical Aspects of Wave Propagation, R. Kleinman (Editor), SIAM, Philadephia, Pennsylvania, 152-160.

Collino, F., and C. Tsogka (2001). Application of the PML absorbing layer model to the linear elastodynamic problem in anisotropic heterogeneous media, Geophysics 66, no. 1, 294-307.

Davis, P. M., J. L. Rubinstein, K. H. Liu, S. S. Gao, and L. Knopoff (2000). Northridge earthquake damage caused by geologic focusing of seismic waves, Science 289, 1746-1750.

Davis, T. L., J. Namson, and R. F. Yerkes (1989). A cross-section of the 


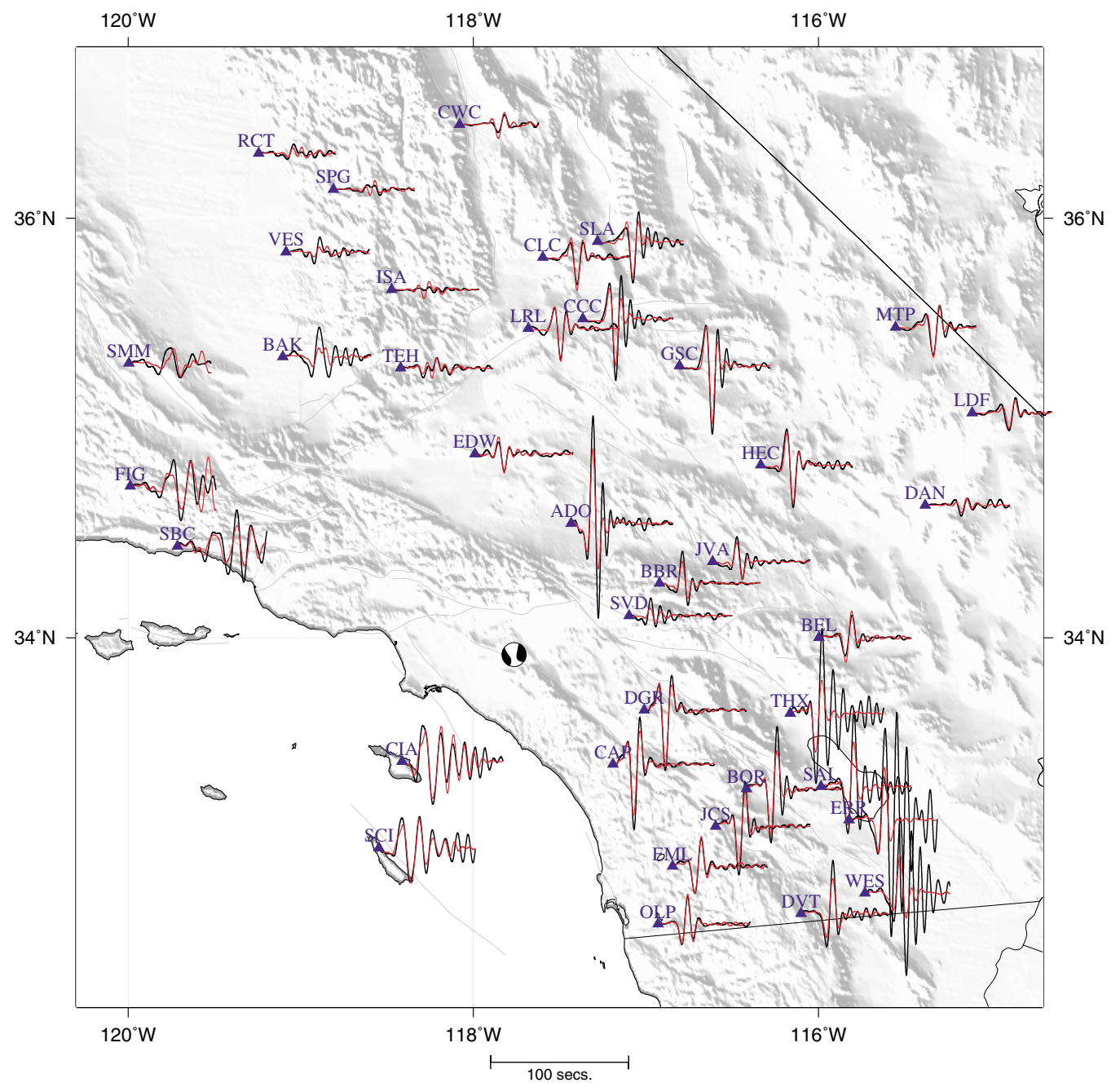

Figure 16. Transverse component data (black) and 3D SEM synthetic seismograms (red) for the 3 September 2002 Yorba Linda event are plotted on a map of southern California. Stations are denoted by blue triangles and labeled by their station codes. The instrument response was deconvolved from the data to obtain ground displacement. Both the data and the synthetic seismograms were subsequently bandpass filtered between 6 and $35 \mathrm{sec}$ with a four-pole two-pass Butterworth filter. In the Salton Sea area (for instance at stations SAL, ERR, and WES) and in the Mojave Desert (e.g., at station ADO), there is substantial low wave-speed sediment cover that is not yet included in our model, which causes resonance in the data that is not correctly reproduced.

Los Angeles area: seismically active fold-and-thrust belt, the 1987 Whittier Narrows earthquake, and earthquake hazard, J. Geophys. Res. 94, 9644-9664.

Dreger, D. S., and D. V. Helmberger (1990). Broadband modeling of local earthquakes, Bull. Seism. Soc. Am. 80, 1162-1179.

Eisner, L., and R. W. Clayton (2002). A full waveform test of the southern California velocity model by the reciprocity method, Pure Appl. Geophys. 159, 1691-1706.

Faccioli, E., F. Maggio, R. Paolucci, and A. Quarteroni (1997). 2D and 3D elastic wave propagation by a pseudo-spectral domain decomposition method, J. Seism. 1, 237-251.

Frankel, A. (1993). Three-dimensional simulations of ground motions in the San Bernardino valley, California, for hypothetical earthquakes on the San Andreas fault, Bull. Seism. Soc. Am. 83, 1020-1041.

Frankel, A., and W. Leith (1992). Evaluation of topographic effects on $P$ and $S$ waves of explosions at the northern Novaya Zemlya test site using 3-D numerical simulations, Geophys. Res. Lett. 19, 1887-1890.
Frankel, A., and J. Vidale (1992). A three-dimensional simulation of seismic waves in the Santa Clara valley, California, from the Loma Prieta aftershock, Bull. Seism. Soc. Am. 82, 2045-2074.

Fuis, G. S., R. W. Clayton, P. M. Davis, T. Ryberg, W. J. Lutter, D. A. Okaya, E. Hauksson, C. Prodehl, J. M. Murphy, M. L. Benthien, S. A. Baher, M. D. Kohler, K. Thygesen, G. Simila, and G. R. Keller (2003). Fault systems of the 1971 San Fernando and 1994 Northridge earthquakes, southern California: relocated aftershocks and seismic images from LARSE II, Geology 31, 171-174.

Gaffet, S., and M. Bouchon (1989). Effects of two-dimensional topographies using the discrete wavenumber-boundary integral equation method in P-SV cases, J. Acoust. Soc. Am. 85, 2277-2283.

Gao, S., H. Liu, P. M. Davis, and L. Knopoff (1996). Localized amplification of seismic waves and correlation with damage due to the Northridge earthquake: evidence for focusing in Santa Monica, Bull. Seism. Soc. Am. 86, no. 18, S209-S230. 
Garatani, K., H. Nakamura, H. Okuda, and G. Yagawa (2000). Large-scale parallel wave propagation analysis by GeoFEM, Lect. Notes Comp. Sci. 1823, 445-453.

Graves, R. W. (1996). Simulating seismic wave propagation in 3D elastic media using staggered-grid finite differences, Bull. Seism. Soc. Am. 86, no. 4, 1091-1106.

Graves, R. W. (1999). Three-dimensional computer simulations of realistic earthquake ground motions in regions of deep sedimentary basin, in The Effects of Surface Geology on Seismic Motion, K. Irikura, K. Kudo, H. Okada, and T. Sasatani (Editors), Vol. 1, Balkema, Rotterdam, The Netherlands, 103-120.

Gropp, W., E. Lusk, N. Doss, and A. Skjellum (1996). A high-performance, portable implementation of the MPI message passing interface standard, Parallel Comput. 22, no. 6, 789-828.

Hadley, D., and H. Kanamori (1977). Seismic structure of the Transverse Ranges, California, Geol. Soc. Am. Bull. 88, 1469-1478.

Hartzell, S., S. Harmsen, A. Frankel, D. Carver, E. Cranswick, M. Meremonte, and J. Michael (1998). First-generation site-response maps for the Los Angeles region based on earthquake ground motions, Bull. Seism. Soc. Am. 88, 463-472.

Hartzell, S. H., A. Leeds, A. Frankel, and J. Michael (1996). Site response for urban Los Angeles using aftershocks of the Northridge earthquake, Bull. Seism. Soc. Am. 86, no. 18, S168-S192.

Hauksson, E. (1990). Earthquakes, faulting, and stress in the Los Angeles basin, J. Geophys. Res. 95, 15,365-15,394.

Hauksson, E. (2000). Crustal structure and seismicity distribution adjacent to the Pacific and North America plate boundary in southern California, J. Geophys. Res. 105, 13,875-13,903.

Hauksson, E., and J. S. Haase (1997). Three-dimensional $V_{\mathrm{p}}$ and $V_{\mathrm{p}} / V_{\mathrm{s}}$ velocity models of the Los Angeles basin and central Transverse Ranges, California, J. Geophys. Res. 102, 5423-5453.

Hauksson, E., T. L. Teng, and T. L. Henyey (1987). Results from a $1500 \mathrm{~m}$ deep, three-level downhole seismometer array: site response, low $Q$ values, and $f_{\max }$, Bull. Seism. Soc. Am. 77, 1883-1904.

Huftile, G. J., and R. S. Yeats (1995). Convergence rates across a displacement transfer zone in the western Transverse Ranges, Ventura basin, California, J. Geophys. Res. 100, no. 2, 2043-2067.

Ichinose, G. A., S. M. Day, H. Magistrale, T. Prush, F. Vernon, and A. Edelman (1996). Crustal thickness variations beneath the Peninsular Ranges, southern California, Geophys. Res. Lett. 23, 3095-3098.

Igel, H. (1999). Wave propagation in three-dimensional spherical sections by the Chebyshev spectral method, Geophys. J. Int. 136, 559-566.

Jennings, P. (1975). Fault map of California with volcanoes, thermal springs, and thermal wells at 1:750,000 scale, in Geological Data Map 1, California Division of Mines and Geology, Sacramento, California.

Ji, C., D. V. Helmberger, and D. J. Wald (2000). Basin structure estimation by waveform modeling: forward and inverse methods, Bull. Seism. Soc. Am. 90, 964-976.

Ji, C., D. J. Wald, and D. V. Helmberger (2002). Source description of the 1999 Hector Mine, California earthquake, part I: Wavelet domain inversion theory and resolution analysis, Bull. Seism. Soc. Am. 92, 1192-1207.

Komatitsch, D. (1997). Méthodes spectrales et éléments spectraux pour l'équation de l'élastodynamique $2 \mathrm{D}$ et $3 \mathrm{D}$ en milieu hétérogène (Spectral and spectral-element methods for the 2D and 3D elastodynamics equations in heterogeneous media), Ph.D. thesis, Institut de Physique du Globe, Paris, France.

Komatitsch, D., and J. Tromp (1999). Introduction to the spectral-element method for 3-D seismic wave propagation, Geophys. J. Int. 139, 806822.

Komatitsch, D., and J. Tromp (2001). Modeling of seismic wave propagation at the scale of the Earth on a large Beowulf, Proc. of the ACM/ IEEE Supercomputing SC'2001 Conference, Denver, Colorado, 1016 November 2001, CD-ROM, www.sc-conference.org/.

Komatitsch, D., and J. Tromp (2002a). Spectral-element simulations of global seismic wave propagation, I. Validation, Geophys. J. Int. 149, 390-412.
Komatitsch, D., and J. Tromp (2002b). Spectral-element simulations of global seismic wave propagation, II. 3-D models, oceans, rotation, and self-gravitation, Geophys. J. Int. 150, 303-318.

Komatitsch, D., and J. Tromp (2003). A perfectly matched layer absorbing boundary condition for the second-order seismic wave equation, Geophys. J. Int. 154, 146-153.

Komatitsch, D., and J. P. Vilotte (1998). The spectral-element method: an efficient tool to simulate the seismic response of 2D and 3D geological structures, Bull. Seism. Soc. Am. 88, no. 2, 368-392.

Komatitsch, D., S. Tsuboi, C. Ji, and J. Tromp (2003). A 14.6 billion degrees of freedom, 5 teraflops, 2.5 terabyte earthquake simulation on the Earth Simulator, Proc. of the ACM/IEEE Supercomputing SC'2003 Conference, Phoenix, Arizona, 15-21 November, CD-ROM, www.sc-conference.org.

Komatitsch, D., J. P. Vilotte, R. Vai, J. M. Castillo-Covarrubias, and F. J. Sánchez-Sesma (1999). The spectral element method for elastic wave equations: application to 2D and 3D seismic problems, Int. J. Numer. Meth. Eng. 45, 1139-1164.

Kristek, J., P. Moczo, K. Irikura, T. Iwata, and H. Sekiguchi (1999). The 1995 Kobe mainshock simulated by 3D finite differences, in The Effects of Surface Geology on Seismic Motion, K. Irikura, K. Kudo, H. Okada, and T. Sasatani (Editors), Vol. 3, Balkema, Rotterdam, The Netherlands, 1361-1368.

Larsen, S., M. Antolik, D. Dreger, C. Stidham, C. Schultz, A. Lomax, and B. Romanowicz (1997). 3-D models of seismic wave propagation: Simulating scenario earthquakes along the Hayward fault, Seism. Res. Lett. 68, 328.

Lewis, J., S. M. Day, H. Magistrale, J. Eakins, and F. L. Vernon (2000). Crustal thickness of the Peninsular Ranges, southern California, from teleseismic receiver functions, Geology 28, 303-306.

Liu, Q., D. Komatitsch, and J. Tromp (2002). Spectral-element centroidmoment tensor inversions, EOS 83.

Luyendyk, B. P., and J. S. Hornafius (1987). Neogene crustal rotations, fault slip and basin development in southern California, in Cenozoic Basin Development of Coastal California, R. V. Ingersoll and W. G. Ernst (Editors), Prentice Hall, New York, 259-283.

Lysmer, J., and L. A. Drake (1972). A finite element method for seismology, in Methods in Computational Physics, Vol. 11, Academic, New York.

Magistrale, H., S. Day, R. W. Clayton, and R. Graves (2000). The SCEC Southern California reference three-dimensional seismic velocity model version 2, Bull. Seism. Soc. Am. 90, S65-S76.

Magistrale, H., K. McLaughlin, and S. Day (1996). A geology based 3-D velocity model of the Los Angeles basin sediments, Bull. Seism. Soc. Am. 86, 1161-1166.

McCulloh, T. H. (1960). Gravity variations and the geology of the Los Angeles basin of California, U.S. Geol. Surv. Profess. Pap. 400-B, 320-325.

McLaughlin, K. L., and S. M. Day (1994). 3-D elastic finite-difference seismic wave simulations, Comput. Phys. 8, no. 6, 656-663.

Moczo, P., E. Bystrický, J. Kristek, J. M. Carcione, and M. Bouchon (1997). Hybrid modeling of $P-S V$ seismic motion at inhomogeneous viscoelastic topographic structures, Bull. Seism. Soc. Am. 87, 1305-1323.

Namson, J., and T. L. Davis (1992). Late Cenozoic thrust ramps of southern California, technical report, Davis \& Namson Consulting Geologists, Valencia, California, unpublished report.

Olsen, K. B. (2000). Site amplification in the Los Angeles basin from threedimensional modeling of ground motion, Bull. Seism. Soc. Am. 90, S77-S94.

Olsen, K. B., and R. J. Archuleta (1996). 3-D simulation of earthquakes on the Los Angeles fault system, Bull. Seism. Soc. Am. 86, no. 3, 575596.

Olsen, K. B., S. M. Day, and C. R. Bradley (2003). Estimation of $Q$ for long-period ( $>2 \mathrm{sec}$ ) waves in the Los Angeles basin, Bull. Seism. Soc. Am. 93, no. 2, 627-638.

Olsen, K. B., R. Madariaga, and R. J. Archuleta (1997). Three-dimensional 
dynamic simulation of the 1992 Landers earthquake, Science 278, 834-838.

Olsen, K. B., J. C. Pechmann, and G. T. Schuster (1995). Simulation of 3D elastic wave propagation in the Salt Lake basin, Bull. Seism. Soc. Am. 85, 1688-1710.

Patera, A. T. (1984). A spectral element method for fluid dynamics: laminar flow in a channel expansion, J. Comput. Phys. 54, 468-488.

Peyrat, S., K. B. Olsen, and R. Madariaga (2001). Dynamic modeling of the 1992 Landers earthquake, J. Geophys. Res. 106, 26,467-26,482.

Pitarka, A., and K. Irikura (1996a). Modeling 3D surface topography by a finite-difference method: Kobe-JMA station site, Japan, case study, Geophys. Res. Lett. 23, 2729-2732.

Pitarka, A., and K. Irikura (1996b). Basin structure effects on long period strong motions in the San Fernando valley and the Los Angeles basin from the 1994 Northridge earthquake and aftershocks, Bull. Seism. Soc. Am. 86, no. 18, S126-S137.

Priolo, E., J. M. Carcione, and G. Seriani (1994). Numerical simulation of interface waves by high-order spectral modeling techniques, $J$. Acoust. Soc. Am. 95, no. 2, 681-693.

Rial, J. A. (1996). The anomalous seismic response of the ground at the Tarzana Hill site during the Northridge 1994 Southern California earthquake: a resonant, sliding block? Bull. Seism. Soc. Am. 86, 17141723.

Satoh, T., H. Kawase, T. Sato, and A. Pitarka (2001). Three-dimensional finite-difference waveform modeling of strong motions observed in the Sendai basin, Japan, Bull. Seism. Soc. Am. 91, 365-380.

Schneider, C. L., C. Hummon, R. S. Yeats, and G. J. Huftile (1996). Structural evolution of the northern Los Angeles basin, California, based on growth strata, Tectonics 15, 341-355.

Seriani, G., and E. Priolo (1994). A spectral element method for acoustic wave simulation in heterogeneous media, Finite Elem. Anal. Des. 16, 337-348.

Shaw, J. H., and P. Shearer (1999). An elusive blind-thrust fault beneath metropolitan Los Angeles, Science 283, 1516-1518.

Shaw, J. H., and J. Suppe (1996). Earthquake hazards of active blind-thrust faults under the central Los Angeles basin, California, J. Geophys. Res. 101, 8623-8642.

Spudich, P., M. Hellweg, and W. H. K. Lee (1996). Directional topographic site response at Tarzana observed in aftershocks of the 1994 Northridge, California, earthquake: implications for mainshock motions, Bull. Seism. Soc. Am. 86, no. 18, S193-S208.

Stevens, J. L., K. L. McLaughlin, B. Shkoller, and S. M. Day (1993). 2-D axisymmetric calculations of surface waves generated by an explosion in an island, mountain and sedimentary basin, Geophys. J. Int. 114, $548-560$.

Stidham, C., M. Antolik, D. Dreger, S. Larsen, and B. Romanowicz (1999). Three-dimensional structure influences on the strong motion wavefield of the 1989 Loma Prieta earthquake, Bull. Seism. Soc. Am. 89, $1184-1202$.
Stidham, C., M. P. Süss, and J. H. Shaw (2001). 3D density and velocity model of the Los Angeles basin, in Geological Society of America 2001 Annual Meeting Abstracts, Denver, Colorado, Geological Society of America, 33, 299.

Süss, M. P., and J. H. Shaw (2003). P-wave seismic velocity structure derived from sonic logs and industry reflection data in the Los Angeles basin, California, J. Geophys. Res. 108 B3 ESE13, 1-18.

Tessmer, E., D. Kessler, D. Kosloff, and A. Behle (1992). Multi-domain Chebyshev-Fourier method for the solution of the equations of motion of dynamic elasticity, J. Comput. Phys. 100, 355-363.

U.S. Geological Survey (2003) (USGS). U. S. Geological Survey Southern California topography map, www.usgs.gov (last accessed December 2003).

Virieux, J. (1986). $P-S V$ wave propagation in heterogeneous media: velocitystress finite-difference method, Geophysics 51, 889-901.

Wald, D. J., and R. W. Graves (1998). The seismic response of the Los Angeles basin, California, Bull. Seism. Soc. Am. 88, 337-356.

Wald, D. J., T. H. Heaton, and K. W. Hudnut (1996). The slip history of the 1994 Northridge, California, earthquake determined from strong ground motion, teleseismic, GPS, and leveling data, Bull. Seism. Soc. Am. 86, S49-S70.

Wright, T. L. (1991). Structural geology and tectonic evolution of the Los Angeles basin, California, in Active Margin Basins, K. T. Biddle (Editor), Am. Assoc. Pet. Geol. Memoir, Vol. 52, 35-134.

Yeats, R. S., G. J. Huftile, and L. T. Stitt (1994). Late Cenozoic tectonics of the east Ventura basin, Transverse Ranges, California, Am. Assoc. Petrol. Geol. Bull. 78, no. 7, 1040-1074.

Zahradník, J., P. Moczo, and F. Hron (1993). Testing four elastic finitedifference schemes for behavior at discontinuities, Bull. Seism. Soc. Am. 83, 107-129.

Zhu, L., and H. Kanamori (2000). Moho depth variation in southern California from teleseismic receiver functions, J. Geophys. Res. 105, 2969-2980.

Seismological Laboratory

California Institute of Technology

1200 E. California Blvd.

Pasadena, California 91125

(D.K., Q.L., J.T.)

Department of Earth and Planetary Sciences

Harvard University

20 Oxford St.

Cambridge, Massachusetts 02138

(P.S., C.S., J.H.S.)

Manuscript received 21 April 2003. 